\title{
LAS INTELIGENCIAS MÚLTIPLES: EVALUACIÓN Y RELACIÓN CON EL RENDIMIENTO EN MATEMÁTICA EN ESTUDIANTES DEL QUINTO AÑO DE SECUNDARIA DE LIMA METROPOLITANA
}

\author{
THE MULTIPLE INTELLIGENCE: EVALUATION AND RELATIONSHIP WITH THE \\ YIELD IN MATHEMATICS IN STUDENTS OF THE FIFTH YEAR OF SECONDARY \\ OF LIMA METROPOLITAN
}

Jaime Aliaga T. ${ }^{1}$, Carlos Ponce D., Mario Bulnes B., Roger Elizalde B. (†), William Montgomery U., Victor Gutiérrez O., Eliana Delgado C., José Perea R, Richard Torchiani G.

Universidad Nacional Mayor de San Marcos, Lima, Perú

(RECIBIDO 09/11/2012 - AcEPTAdo 2/12/2012)

\begin{abstract}
RESUMEN
La teoría de las inteligencias múltiples representa una visión innovadora en el campo de la psicología de la educación, pues brinda un marco diferente para el mejor encuadre del proceso de enseñanza-aprendizaje, haciendo posible que el alumno identifique mejor sus puntos intelectuales fuertes y débiles; y que, con esta información, el docente seleccione los recursos y estrategias didácticas para que en trabajo conjunto aquel desarrolle aún más los más fuertes y mejore los débiles, siempre buscando el logro de su satisfacción personal y éxito profesional. En esta perspectiva, la evaluación de las inteligencias múltiples, de una manera válida y confiable, adquiere fundamental importancia, por lo que al no existir en el país instrumentos con estas características decidimos elaborar uno; además, interesados también en la problemática del bajo rendimiento escolar en matemáticas, decidimos someter a contraste la hipótesis que la inteligencia múltiple lógico matemática se relaciona de manera más elevada que las otras inteligencias múltiples con el rendimiento escolar en matemática, y más con este que con el rendimiento académico general. Se elaboró el Cuestionario de Inteligencias Múltiples (CUIM) basado en el marco teórico propuesto por Gardner, empleándose para establecer sus características psicométricas una muestra de 1291 estudiantes de ambos sexos del quinto año de secundaria y estudiantes universitarios y preuniversitarios con un decidido interés por la carrera a seguir, y por pintores y danzantes. La hipótesis fue contrastada en una segunda muestra compuesta por 960 estudiantes del quinto año de secundaria. Los estudiantes secundarios de ambas muestras provinieron de 14 instituciones educativas de gestión estatal y privada ubicadas en los diversos distritos de Lima Metropolitana. Los resultados indican que el CUIM tiene características psicométricas de confiabilidad y validez que lo avalan como un instrumento adecuado para el logro de su propósito, y que la hipótesis es apoyada por los datos.
\end{abstract}

Palabras clave: inteligencias múltiples, rendimiento en matemáticas, estudiante secundario. 


\begin{abstract}
The theory of the Multiple Intelligence represents an innovative vision in the field of the psychology of the education, because it offers a different mark for the best alignment in the teaching-learning process, making possible that the student identifies his strong and weak intellectual points better; and that, with this information, the or the educational one selects the resources and didactic strategies so that in work group that it develops even more the strongest and improve the weak ones, always looking for the achievement of their personal satisfaction and professional success. In this perspective, the evaluation of the multiple intelligence in a valid and reliable way acquires fundamental importance, for what we decide to elaborate one when not existing in the country instruments with these characteristics; also, also interested in the problem of the first floor school yield in mathematics, to subject to contrast the hypothesis that the Intelligence Multiple Logical Mathematics will be related in a higher way that the other multiple intelligence with the school yield in mathematics, and more with this than with the general academic yield. The Questionnaire of Multiple Intelligence was elaborated (CUIM) based on the frame of Gardner, using stops to establish its psychometric properties a sample of 1291 people of both sexes, the fifth year-old students, university students and preuniversitarys with a resolved interest for the career to continue, and for painters and dancers. The hypothesis was contrasted in a second sample composed by 960 students the fifth years of secondary. The secondary students of both samples came from 14 educational institutions of state and private administration located in the diverse districts of Metropolitan Lima. The results indicate that the CUIM has psychometric characteristic of reliability and validity that endorse it as an appropriate instrument for the achievement of its purpose, and that the hypothesis is supported by the data.
\end{abstract}

Keywords: multiple intelligence, yield in mathematics, secondary student

\title{
INTRODUCCIÓN
}

El bajo rendimiento en matemáticas (y en comprensión lectora) de los escolares peruanos ha sido puesto en evidencia reiteradamente de acuerdo al análisis de varias evaluaciones realizadas por organismos nacionales e internacionales en los últimos quince años (p.e. Torreblanca, 2001). Recientemente, en la Evaluación Censal 2011 realizada por la Unidad de Medición de la Calidad Educativa (UMC) del MINEDU se encontró que solamente el 13,2\% de los estudiantes del segundo grado de primaria de todo el país logró los aprendizajes esperados para el grado, en tanto que el $35,8 \%$ no los logró, pero es capaz de resolver problemas matemáticos sencillos; y, el $51 \%$ tampoco los logró, pero, además, tienen dificultades para resolver situaciones matemáticas sencillas. Por otro lado, el 2009 en el marco del Programa Internacional para la Evaluación de Estudiantes (PISA) de la Organización para la Cooperación y el Desarrollo Económico (OCDE), se evaluó a estudiantes de quince años de edad próximos a cumplir su educación obligatoria. Se midió la capacidad para poner en práctica sus habilidades y conocimientos necesarios para hacer frente a desafíos que plantea la vida real en el contexto de una sociedad del conocimiento. Participaron 65 países, entre ellos ocho de Latinoamérica: Perú, Argentina, Brasil, Chile, México, Colombia, Panamá y Uruguay. El puntaje promedio de los países de la OCDE fue 496, el de los países 
latinoamericanos 393 y el de los estudiantes peruanos 365 puntos ocupando el intervalo $61-65$ entre los países participantes. En referencia a niveles de rendimiento, sobre una escala del 1 (más bajo) al 6 (más alto) solamente el $0,1 \%$ de nuestros estudiantes alcanzó el nivel 6 y el 47,6\% se situó en un nivel inferior al 1 (menos de 338 puntos).

Estos datos grafican una realidad con características de mucha pobreza en la calidad de los logros en matemáticas en la educación primaria y secundaria y, presumimos por el carácter continuo del sistema educativo, en la educación superior no universitaria y universitaria, matizada por las peculiaridades que tiene este nivel educativo (Chávez, 1991). Esta situación es bastante preocupante, pues cada vez se acepta más la importancia de la matemática en una amplia gama de áreas desde las disciplinas técnicas hasta el ámbito de las ciencias humanas y del comportamiento, por su capacidad para tratar rigurosa y analíticamente los objetos y fenómenos, porque su dominio es básico para el desarrollo de la investigación y porque hay una correlación entre el grado de avance de los países y el desarrollo de las ciencias formales lógicas y matemáticas de sus habitantes (Flores, 1996), que cristaliza en una cultura o "alfabetización científica" (Martínez, 1997) y una "alfabetización tecnológica" (Bybee, 2002, en Valdes, Guisasola y Santos, 2002: 103), que se evidencia en el manejo de los mínimos conceptos y hechos científicos a fin de entender asuntos económicos, médicos, ambientales y otros temas necesarios para desenvolverse adecuadamente en las nuevas sociedades que se vienen formando.

En una economía cada vez más globalizada es un hecho que el tipo y calidad de las ventajas que un país obtenga depende del grado de su avance científico-tecnológico, a su vez muy relacionado con el nivel de conocimientos que en matemáticas y en ciencias tenga la mayoría de su población. En nuestro entender esta constatación es una de las razones por las que el gobierno peruano el 2003 decretó la Emergencia Educativa buscando redefinir las bases y el accionar educativo en pos de lograr una de las situaciones-meta propuestas para el año 2021, elevar sustancialmente el rendimiento de los alumnos del Perú, los que alcanzarán el rendimiento medio de la población mundial (Comisión para un Acuerdo Nacional por la Educación. Conclusiones, 2001).

El revertir la situación descrita es entonces tarea impostergable. Con el fin de colaborar a este propósito realizamos este estudio en alumnos del quinto año de secundaria porque en términos generales su nivel real de rendimiento escolar en matemática y en las demás asignaturas es más evidente respecto, por ejemplo, del que han tenido en el primer año por el efecto acumulativo de este rendimiento. En este camino es necesario tener en cuenta a una referencia obligada cuando se trata de la enseñanza de las matemáticas, el Informe Cokcroft (1985) -basado en la realidad del Reino Unido- que a lo largo de los años ha ganado influencia en la enseñanza de la matemática tanto dentro como fuera de su país de origen (Rivieré, 2002). Allí entre los más de seiscientos puntos que contiene se asevera que la matemática es una asignatura difícil de enseñar y de aprender lo que está en estrecha relación con la jerarquización de sus contenidos, que no todos los 
niños aprenden a la misma velocidad aún con los mismos contenidos, que obliga a practicar mucho con independencia del nivel de conocimientos que se tenga, que el planteamiento del problema es el aspecto más difícil de resolución de un problema de matemático no debiendo subestimarse la imaginación que se precisa para ello; asimismo, que la actitud juega un rol importante en el aprendizaje y uso de las matemáticas (Cokcroft, 1985). Este informe sirvió de inspiración para la elaboración de diversos modelos que intentan describir, explicar y comprender el proceso de enseñanza-aprendizaje de la matemática, entre ellos el modelo psicoeducativo en matemática que tiene como un componente esencial, junto con otros no menos importantes como el profesor, al alumno o sujeto que aprende con sus cualidades psicológicas (Beltrán 1987, en Nortes, 1993).

Entre estas cualidades psicológicas está desde nuestro punto de vista la inteligencia. La palabra inteligencia es un término antiguo que recién aparece en la bibliografía psicológica en los primeros años del siglo XX, pues antes predominaba la doctrina de las facultades refiriéndola en términos de juicio, razonamiento o intelecto. Spearman atribuyó en 1927 el mérito de introducir el término en la psicología a Herbert Spencer en 1895 que la definía como "el poder de combinar muchas impresiones separadas" (Guilford, 1986:26). Desde entonces se han realizado múltiples investigaciones para descifrar su naturaleza y las circunstancias de su manifestación. Los primeros estudios sobre este constructo se originaron en un interés pragmático centrado en la elaboración de los tests mentales más que en un interés teórico; por ejemplo, Binet y Simon en 1905 publicaron Méthodes Nouvelles pour le diagnostic du niveau intellectuel des anormaux -presentado años más tarde en su versión estadounidense como el Test Stanford-Binet- reconocido como el primer test de inteligencia con el que se dio inicio a la medición de las funciones cognitivas complejas.

En 1904 el psicólogo inglés Spearman creó uno de los grandes aportes de la psicología a la estadística: el análisis factorial, técnica multivariada de análisis de datos que le sirvió años más tarde para elaborar la teoría bifactorial de la inteligencia que se estima es la primera teoría científica desarrollada en este campo de la psicología. La teoría básicamente se fundamenta en el análisis estadístico de las puntuaciones de diversos tests cognitivos que tuvo como producto un constructo matemático-estadístico al que Spearman nombro factor "g" que subyacería a todos los rendimientos intelectuales (Spearman, 1954), aunque no hay acuerdo en cuanto a su significado, siendo para algunos una habilidad de razonamiento abstracto generalizado y para otros, como Redd y Jensen, un índice de medida de la velocidad de procesamiento sensorial (Redd y Jensen, 1992, en Neisser, 1997). Sin embargo, para muchos psicólogos es claro que "g" sumariza e indica las diferencias individuales en inteligencia, asimilándosele en el uso psicológico común como inteligencia general. La teoría bifactorial representa una concepción unitaria de la inteligencia de notable impacto en la psicología y tema de controversia que trajo por resultado el surgimiento de teorías rivales cuyos autores también hacían uso del análisis factorial pero con ciertas variantes de tipo matemático. 
Thurstone propuso en 1938 su teoría multifactorial de la inteligencia, sosteniendo que esta estaba compuesta por un conjunto limitado de factores o "aptitudes mentales primarias" que se medirían con distintas tareas a los que denominó y simbolizó como comprensión verbal (V), fluidez verbal (W), aptitud numérica $(\mathrm{N})$, visualización espacial (E); memoria de asociación (M), velocidad perceptiva (P) y razonamiento o inducción (R). Casi 30 años después Guilford (1967, en Guilford, 1986) presentó graficándolo como un cubo su modelo tridimensional referido a las actividades cognoscitivas al que denominó "estructura del intelecto", en el que cada una de estas actividades se define por el contenido (figurativo, simbólico, semántico, de conducta), por la operación realizada (evaluación, pensamiento convergente, pensamiento divergente, memoria, conocimiento) y por los productos, que se diferencian por su grado de complejidad (unidades, clases, relaciones, sistemas, transformaciones, implicaciones); resultando del entrecruzamiento de estas dimensiones 120 combinaciones a las que corresponden 120 tipos de tareas a cada una de las cuales está adscrito, teóricamente, un factor que requiere a su vez de un test para su medición. Gardner respaldándose en estudios efectuados por Gould $(1981,1984)$ dice respecto de estas dos teorías que si bien dejaban abierta la idea de diferentes "vectores de la mente" en contraposición a la visión unitaria que representa el factor "g" de Spearman, sus diferencias con esta estriban solamente en la técnica de análisis factorial utilizada pues puede llegarse a una visión unitaria o pluralista de la inteligencia de acuerdo a la técnica empleada (Gardner, 1987, 2006).

Con la aparición de la visión cognitiva en la psicología -el primer libro con el nombre de Psicología Cognitiva lo escribió Neisser en 1967- , empieza a bosquejarse nuevas rutas en el estudio de la inteligencia. En la década de 1980 aparecen dos teorías cognitivo-contextuales que tratan acerca de como los procesos cognitivos operan en varios escenarios. Dos de los mayores teóricos en esta área son Robert Sternberg y Howard Gardner.

En 1985, Sternberg dio a conocer su teoría triárquica de la inteligencia que en comparación a las teorías de Thusrtone y de Guilford es más comprensiva, más abarcadora, ya que toma en cuenta factores contextuales y sociales además de las habilidades humanas. Esta teoría supone tres subteorías: 1) una teoría componencial que especifica la manera en que el desempeño de los metacomponentes o unidades de procesamiento de la información operan. Por ejemplo, en el procesamiento metaconponencial que tiene una función ejecutiva en el intelecto, se determina la naturaleza del problema, se selecciona los componentes de desempeño apropiados para resolver el problema, se monitorea el desempeño, se interpreta la retroalimentación y se modifica el desempeño en respuesta a esta. 2) Una teoría experiencial que relaciona la vida mental del individuo con su experiencia, que varía en un continuo de ninguna experiencia con determinadas tareas y situaciones hasta la total experiencia en la que el procesamiento de la información se presenta completamente automatizado. Este procesamiento automático lleva al crecimiento cognitivo, por ello las experiencias del niño tienen un rol importante en su desarrollo. 3) Una teoría contextual que relaciona el procesamiento de la 
información con los ambientes particulares en los que esto ocurre. En este sentido, el funcionamiento intelectual sería una actividad mental dirigida a la adaptación, selección o moldeamiento de ambientes reales relevantes a la propia vida. Por lo tanto, ambientes diferentes producen necesidades adaptativas diferentes y formas de actividad mental diferentes. Así la actividad mental esencial para una adaptación exitosa a la escolaridad difiere sustancialmente de la actividad necesaria para la adaptación en el hogar. En consecuencia, las influencias sociales y culturales juegan un rol crucial en la cognición y en opinión de Sternberg (1985) deben ser incluidas en los modelos de inteligencia y desarrollo conceptual.

Por su lado, Gardner en 1983 planteó su teoría de las inteligencias múltiples en el libro Frames of Mind: The theory of multiple intelligence (edición castellana 1987, Estructura de la Mente: La teoría de las inteligencias múltiples); que ha tenido una gran aceptación en educación y en la psicología educacional, y es la que suscribimos para el cumplimiento de los propósitos de este estudio. Al igual que Thurstone, Guilford y especialmente Sternberg, adopta una concepción que pluraliza el concepto tradicional de inteligencia describiendo la competencia cognitiva en términos de un conjunto de inteligencias; concepción cuyos orígenes se remontan al año 1967 cuando Gardner -bastante afecto por las artes- se convierte en miembro fundador del grupo de investigación básica llamado Proyecto Zero iniciado por el filósofo del arte Nelson Goodman en la Escuela de Educación de Harvard. Un poco antes interesado en lo que le sucede a las personas normales o superdotadas cuando sufren un daño cerebral, empezó un trabajo que le tomó veinte años tratando de entender la organización de las capacidades humanas en el cerebro. En 1979 un grupo de investigadores de la citada escuela recibió una subvención de la Fundación Bernard Van Leer de Holanda para estudiar el potencial humano, encargándosele a Gardner el escribir un libro acerca de lo que se conocía sobre la cognición humana en las ciencias biológicas y del comportamiento; trabajo con el cual inició el programa de investigación conducente a la teoría de las inteligencias múltiples, que tuvo tres puntos importantes de inflexión: el utilizar el término inteligencias múltiples en lugar de habilidades o dones; la creación de una definición de la inteligencia y de un conjunto de criterios o requisitos sobre lo que es o no es inteligencia; y el análisis de las implicaciones educativas de la teoría (Gardner, 2003).

Inicialmente Gardner caracterizó a la inteligencia como la capacidad de resolver problemas, o de crear productos que sean valiosos en uno o más ambientes culturales (1987); años más tarde, el 2006, paso a definirla como una capacidad computacional -una capacidad para procesar un conjunto de información- que se origina en la biología y en la psicología humana, y que cambia y se desarrolla en función de las experiencias que el individuo puede tener a lo largo de su vida; capacidad que es el resultado de la interacción entre los factores biológicos y ambientales, dependiendo de alguna manera del contexto (Gardner, 2006).

Gardner sostiene que lo que hace al ser propiamente humano es el tener estas inteligencias en mayor o menor medida y que hemos evolucionado para mostrar 
distintas inteligencias y no para recurrir de diversas maneras a una sola inteligencia flexible. Tenemos diferentes perfiles de inteligencia y una inteligencia no es mejor que la otra pues cada una tiene su propia esfera y especialización. En el proceso de definir cada una de las inteligencias elaboró ocho criterios o requisitos distintos fundamentados en pruebas biológicas y antropológicas, entre los que se encuentran el posible aislamiento o destrucción de una facultad específica por lesión cerebral, la existencia de prodigios e idiotas savants, el apoyo de métodos psicológicos experimentales y diversos hallazgos psicométricos (Gardner, 1987, 2006).

Las inteligencias propuestas por Gardner a las que se acompaña una descripción con información tomada del mismo Gardner $(1987,2006)$, de Armstrong (2006), y de Nicholson-Nelson (1998, citado en de Luca, 2009), son las siguientes:

La Inteligencia Lingüística. Capacidad de usar las palabras de manera efectiva, en forma oral o escrita. Incluye la habilidad en el uso de la sintaxis, la fonética, la semántica y los usos pragmáticos del lenguaje (la retórica, la mnemónica, la explicación y el metalenguaje). Se observa en las personas que les agrada redactar historias, leer, jugar con rimas, trabalenguas y en los que aprenden con facilidad otros idiomas. Se aprende mejor leyendo, escuchando y viendo palabras, hablando, escribiendo, discutiendo y debatiendo.

La Inteligencia Musical. Capacidad de percibir, discriminar, transformar y expresar las formas musicales. Incluye la sensibilidad al ritmo, al tono y al timbre. Las personas que la evidencian se sienten atraídas por los sonidos de la naturaleza y por todo tipo de melodías disfrutándolas siguiendo el compás con el pie, golpeando o sacudiendo algún objeto rítmicamente. Se aprende mejor mediante el ritmo, la melodía, escuchando música y cantando.

La Inteligencia Lógico-matemática. Capacidad para usar los números de manera efectiva y de razonar adecuadamente. Incluye la sensibilidad a los esquemas y relaciones lógicas, las afirmaciones y las proposiciones, las funciones y otras abstracciones relacionadas. Las personas que la han desarrollado analizan con facilidad planteos y problemas. Se acercan a los cálculos numéricos, estadísticas y presupuestos con entusiasmo. Se aprende mejor usando pautas y relaciones, clasificando, trabajando con lo abstracto.

La Inteligencia Espacial. Capacidad de pensar en tres dimensiones. Permite percibir imágenes externas e internas, recrearlas, transformarlas o modificarlas, recorrer el espacio o hacer que los objetos lo recorran y producir o decodificar información gráfica. Está en las personas que estudian mejor con gráficos, esquemas, cuadros y les gusta hacer mapas conceptuales y mentales, entendiendo muy bien planos y croquis. Se aprende mejor trabajando con dibujos y colores, visualizando, dibujando.

La Inteligencia Interpersonal. Capacidad de entender a los demás e interactuar eficazmente con ellos. Incluye la sensibilidad a expresiones faciales, la voz, los gestos y posturas y la habilidad para responder. La tienen las personas que disfrutan trabajando en grupo, que son convincentes en sus negociaciones con pares y 
mayores, que entienden a los otros. Se aprende mejor compartiendo, comparando, relacionando, entrevistando, cooperando.

La Inteligencia Intrapersonal. Capacidad de construir una percepción precisa respecto de sí mismo y de organizar y dirigir su propia vida. Incluye la autodisciplina, la autocomprensión y la autoestima. La evidencian las personas que son reflexivas, de razonamiento acertado y que suelen ser consejeros de otros. Se aprende mejor trabajando solo y haciendo proyectos que se desarrollan al ritmo propio, teniendo espacio, reflexionando.

La Inteligencia Corporal-cenestésica. Capacidad para usar todo el cuerpo en la expresión de ideas y sentimientos, y la facilidad en el uso de las manos para transformar elementos. Incluye habilidades de coordinación, destreza, equilibrio, flexibilidad, fuerza y velocidad, como así también la capacidad cinestésica y la percepción de medidas y volúmenes. Se la aprecia en las personas que se destacan en actividades deportivas, danza, expresión corporal y/o en trabajos de construcciones utilizando diversos materiales concretos. También en aquellos que son hábiles en la ejecución de instrumentos. Se aprende mejor tocando, moviéndose, procesando información a través de sensaciones corporales.

La Inteligencia Naturalista. Capacidad de distinguir, clasificar y utilizar elementos del medio ambiente, objetos, animales o plantas, tanto del ambiente urbano como suburbano o rural. Incluye las habilidades de observación, experimentación, reflexión y cuestionamiento de nuestro entorno. Está presente en las personas que aman los animales, las plantas; que reconocen y les gusta investigar características del mundo natural y del hecho por el hombre. Se aprende mejor trabajando en el medio natural, explorando los hábitats de seres vivientes, plantas, animales y tratando temas relacionados con la naturaleza.

Es necesario tener en cuenta para un adecuado conocimiento de estas inteligencias que son conceptualmente y biológicamente independientes unas de otras, lo que implica que un particular alto (o bajo) nivel en una inteligencia, digamos matemática, no significa necesariamente un alto (o bajo) nivel en otra, por ejemplo, el gusto por el lenguaje o la música. Asimismo, que si bien cada persona desarrolla unas más que otras el desempeño en los roles culturales de cualquier grado de complejidad requiere una combinación de inteligencias, por ejemplo, los bailarines requieren habilidades corporales kinestésicas, musicales, interpersonales e inteligencia espacial en varios grados; además, que el tener una de las inteligencias elevada no significa necesariamente que la persona actúe inteligentemente, pues es posible que alguien con un alto nivel de inteligencia matemática pueda usar sus habilidades "realizando importante experimentos en física (...) y a la vez se la pase jugando jugando en un casino todo el día o multiplicando un número de diez dígitos en su cabeza" (Gardner, 2006: 23).

Al definir la inteligencia como una capacidad, sin negar el componente genético, Gardner $(1987,2006)$ la considera como una destreza que se puede acrecentar, pues si bien el ser humano nace con potencialidades marcada por la genética (lo innato, la herencia, condicionamiento biológicos), las mismas se van a desarro- 
llar (en algunos casos deteriorarse) dependiendo del medio ambiente (factores psico-sociales, culturales, psíquicos) (Ander-Egg, 2006), que se concretan en las vivencias de las experiencias propias de todo el proceso evolutivo, en especial de lo vivenciado en el ámbito de la educación formal e informal. Así por ejemplo, ningún músico de elevado nivel de competencia llega a ese nivel sin la instrucción y el ensayo adecuados.

La autonomía de las inteligencias y la interacción entre estas para el desempeño de los roles culturales así como la posibilidad de desarrollarlas, ha hecho que la teoría de las inteligencias múltiples sea innovadora en el campo educativo porque brinda un marco diferente para el mejor encuadre del proceso de enseñanzaaprendizaje, pues cada niño, adolescente o adulto presenta un perfil característico de capacidades diferentes -un espectro de inteligencias- que pueden reforzarse gracias a las oportunidades que ofrezca la educación y un medio rico en materiales y actividades atractivas, pues un punto clave es que "la mayoría de las personas pueden desarrollar todas sus inteligencias hasta conseguir un dominio aceptable de las mismas" (Armstrong, 2006: 44). Este perfil intelectual hace posible, por ejemplo, que el estudiante identifique las capacidades que debe de capitalizar y las que debe compensar, manejándolas mejor "con la ayuda de sus profesores ya que estos podrán seleccionar mejor los recursos y estrategias didácticas para estimular el desarrollo de las inteligencias más elevadas a niveles más altos y mejorar aquellas en las que el alumno se encuentra débil, con el propósito de que el estudiante logre su satisfacción personal y el éxito profesional" (Pérez y Beltrán, 2006:152).

En el contexto de la teoría de Gardner, la inteligencia que estaría comprometida en el rendimiento en matemática sería la lógico-matemática, deducción que ha sido cometida a comprobación en algunos estudios realizados en Sudamérica. Citamos 4 de ellos, 3 realizados en Chile y 1 en Argentina, los que entre sus diversos propósitos correlacionaron esta inteligencia múltiple con el promedio de notas en matemática y el promedio general. Los investigadores chilenos emplearon el test MIDAS para evaluar las inteligencias múltiples y el investigador argentino comunica que las evaluó con una prueba de su creación. Pizarro y Clark (2000) en estudiantes de Valparaíso del segundo año de secundaria encontraron una correlación de $0,47(\mathrm{p}<0,001)[0,41(\mathrm{p}<0,001)$ con el promedio general en notas y 0,48 [p $<0,001$ con el promedio científico (matemática + ciencias naturales)]; el mismo Pizarro (2005), esta vez en alumnos matriculados en el primer año de secundaria de la misma ciudad, halló una correlación 0,37 ( $<<0,01)$; Andrade, Miranda y Freixas (2000) en estudiantes del segundo año de secundaria de Santiago de Chile elaboraron un modelo de regresión múltiple respecto del rendimiento en matemáticas en el que la inteligencia lógico matemática explicaba el 14,2\% y la inteligencia lingüística el $1,2 \%$ de la variabilidad en el rendimiento. Castro (2008) en estudiantes secundarios de Buenos Aires de alto y bajo rendimiento global encontró vía análisis discriminante una función que explicaba el 18\% de la varianza, en su mayor parte debido a la inteligencia lógico-matemática y en una pequeña parte a la inteligencia intrapersonal. 
Sintetizando las ideas expresadas hasta aquí, hipotetizamos que es la inteligencia múltiple lógico matemática del estudiante del quinto año de secundaria la que se relacionará de manera más elevada que las otras inteligencias múltiples con el rendimiento escolar en matemáticas, y más con éste que con el rendimiento escolar general. Por otro lado, ambos rendimientos se miden utilizando las notas en escala vigesimal que alcanzan los alumnos en las áreas del Diseño Curricular Nacional correspondiente a dicho año escolar; notas que tienen limitaciones pero en la práctica han sido, son y seguirán siendo probablemente durante más tiempo el indicador del citado rendimiento. Al comprobarse la relación hipotetizada podrá explicarse en parte la naturaleza del rendimiento en matemática de nuestros estudiantes y por ser las inteligencias múltiples educables la información generada puede utilizarse para fundamentar más y mejor las estrategias de intervención psicoeducativa, educativa y otras conexas a estas, con la finalidad de contribuir a elevar sustancialmente el rendimiento en matemática, una de las situaciones-meta propuestas para el año 2021.

Por otra parte, en la evaluación de las inteligencias múltiples la observación del sujeto en variadas situaciones de la vida real como las que se presentan en la vida escolar es la técnica de obtención de información preferida por Gardner, la que se centra en comportamientos o "productos" que el sujeto está elaborando o ha elaborado y que son tomados como indicadores de las inteligencias múltiples, por ejemplo el hacer poemarios, indicador de inteligencia lingüística, o el disecar insectos, indicador de inteligencia naturalista (Gardner, 1987, 2006). En el proceso de evaluación también se usa la observación que el sujeto hace en si mismo respecto del contenido de listados "de experiencias reales que el sujeto ya ha vivido en cada una de las ocho inteligencias (Armstrong, 2006:38); listados que al analizarlos según la clasificación de tipos de respuestas solicitadas a los sujetos (Nunally, 1987) expresan juicios, sentimientos y juicios de lo que el sujeto cree que otras personas piensan de él en referencia al contenido (por ejemplo: "Soy capaz de calcular operaciones numéricas mentalmente sin esfuerzo" -juicio).

Sin embargo, Gardner también ha respaldado en Estados Unidos un intento psicométrico de evaluación de las inteligencias con ítems parecidos a los de los listados, las Escalas de Inteligencias Múltiples de Shearer denominada MIDAS (Multiple Intelligence Developmental Assessment Scales) (Shearer, 1995), que además de información cualitativa brinda información del perfil de las inteligencias múltiples, de las habilidades asociadas a cada una de ellas y del estilo intelectual del sujeto en relación a la innovación, la lógica general y el liderazgo.

En este contexto, realizamos esta investigación que tiene por objetivos el elaborar con base en los citados listados, en otras fuentes de información y en el marco de la Teoría Clásica de los Test (TCT) (Spearman, 1954; Muñiz, 1994), un cuestionario válido, confiable y con normas de interpretación de sus puntuaciones según los estándares psicométricos para su uso en el país, cuyos resultados ayuden al psicólogo, profesor, orientador, tutor, a conocer mejor como el estudiante percibe y valora sus inteligencias múltiples; $y$, el determinar la relación de la inteligencia 
múltiple lógico- matemática y de las otras inteligencias múltiples con el rendimiento escolar en matemáticas y el rendimiento escolar general.

\section{MÉTODO}

Tipo de investigación. El estudio tiene dos partes claramente definidas, la primera concierne a la elaboración del Cuestionario de Inteligencias Múltiples (CUIM), y la segunda a la contrastación de la hipótesis enunciada. En ambos casos el enfoque es cuantitativo, correspondiendo la primera parte a un estudio psicométrico (Alarcón, 2008) y la segunda a un estudio correlacional (Hernández, Fernández y Baptista, 2010)

Diseño de investigación. Es transeccional y correlacional pues se recolectaron los datos en un solo momento en el tiempo, y porque se correlaciona las inteligencias múltiples (o variables independientes) con el rendimiento escolar en matemáticas y el rendimiento general (Hernández, Fernández y Baptista, 2010)

Muestra. Se utilizaron dos muestras de sujetos. La primera fue necesaria para la elaboración del Cuestionario de Inteligencias Múltiples (CUIM) y estuvo compuesta por 1291 estudiantes de ambos sexos que cursaban el quinto año de secundaria o eran estudiantes preuniversitarios con un decidido interés por las carreras de psicología, farmacia y bioquímica, estomatología, ingeniería, medicina y administración de negocios. Además de un grupo relativamente pequeño de pintores y bailarines. La segunda fue necesaria para el contraste de la hipótesis, estuvo conformada por 960 estudiantes de ambos sexos del quinto año de secundaria. Tanto en la primera como en la segunda muestra los estudiantes secundarios provinieron de 14 instituciones educativas de gestiones estatal y privada ubicadas en los diversos distritos de Lima Metropolitana.

Procedimiento. Para el logro de los objetivos y el contraste de la hipótesis se siguió el procedimiento siguiente:

1) Se elaboró en base a la teoría de Gardner expuesta en varios libros (Gardner 1987, 2006) el marco teórico del Cuestionario de Inteligencias Múltiples (CUIM).

2) Con fundamento en este marco y en los listados de experiencias que el sujeto ha vivido respecto de las inteligencias múltiples (Armstrong, 2006), se definieron conceptualmente y operacionalmente cada una de las inteligencias múltiples.

3) Se elaboraron los reactivos redactándolos en forma de frases que ponen de manifiesto juicios, sentimientos y juicios de lo que el sujeto cree que otras personas piensan de él en referencia al contenido (Nunally, 1987). En atención al marco teórico se decidió que cada inteligencia estuviera representada por el mismo número de ítems, 10; asimismo, considerando que los sujetos tienen capacidad discriminativa y para propiciar teóricamente una buena confiabilidad, se resolvió que los respuestas se dieran en una escala bipolar numérica del 1 al 7 describiendo las dos respuestas extremas (Morales, 2011) con las frases "De ninguna manera es cierto en mi caso" (1) y "Es totalmente cierto en mi caso" (7). De esta manera el puntaje máximo posible de alcanzar en cada escala/inteligencia múltiple es 70 y el mínimo, 7. 
4) Se realizó una aplicación piloto del cuestionario elaborado en una muestra de 58 universitarios ingresantes a la carrera de psicología a los que se les pidió que aparte de sus respuestas dieran sugerencias acerca de la legibilidad y comprensibilidad de los reactivos. Como resultado se introdujo algunas modificaciones en la redacción de varios de los elementos.

5) La versión resultante fue sometida al escrutinio de diez jueces para determinar su validez de contenido. Los jueces fueron cinco psicólogos docentes de asignaturas de metodología de investigación, psicometría y construcción de pruebas psicológicas, y cinco profesores que habían participado como expositores en talleres sobre las inteligencias múltiples. Se les solicitó su opinión acerca de varios aspectos del cuestionario, por ejemplo, la calidad y pertinencia de las definiciones de las inteligencias, la relevancia, representatividad de los ítems y calidad de redacción; y que sus respuestas las anotaran en un formato elaborado para tal fin. El grado de acuerdo de los jueces se determinó empleando el coeficiente V de Aiken (Escurra, 1988).

6) El cuestionario fue administrado a los sujetos de la muestra por psicólogos y/o estudiantes de psicología capacitados previamente para esta actividad guardando las consideraciones psicométricas que exige el caso.

7) En conexión con la confiabilidad y validez que son las propiedades psicométricas básicas de las puntuaciones de un test en la población estudiada, se realizó un análisis de los ítems con el fin de precisar la capacidad discriminatoria del reactivo para diferenciar a los sujetos de más alta y baja puntuación en la escala/inteligencia múltiple. Se emplearon dos técnicas. La primera, de los "grupos extremos", se efectuó comparando estadísticamente las medias aritméticas de cada uno de los ítems logrados por el grupo de sujetos con más elevada puntuación en la escala ( $25 \%$ superior) y los sujetos del grupo de más baja puntuación en la misma ( $25 \%$ inferior). La comparación se hizo mediante la prueba $\mathrm{T}$ de Student que debía tener un valor mínimo de 1,96 $(\mathrm{p}<0,05)($ Clark-Carter, 2002: 553) para caracterizar al ítem como discriminativo. La segunda sirvió para calcular el Indice de Homogeneidad del ítem (IH) que informa el grado de semejanza, de relación entre las respuestas a un determinado ítem y el resto de los ítems de la escala. Es decir, informa el grado en que dicho ítem está midiendo lo mismo que la escala global. El cálculo se efectuó usando el coeficiente de correlación de Pearson cuyo valor se corrigió eliminando el efecto del propio ítem sobre el puntaje total (correlación ítem-total corregido o ítem remainder); se fijó como criterio de aceptabilidad del ítem el valor 0,20 como mínimo (Ary, Jacobs y Razavieh, 1999). En vista de que las dos técnicas no brindan necesariamente los mismos resultados se decidió que para permanecer en la escala el ítem tenía que cumplir por lo menos con uno de los dos criterios.

8) La fiabilidad de las puntuaciones se determinó analizando la consistencia interna de cada una de las ocho escalas/inteligencias múltiples mediante el coeficiente alfa de Crombach, que es el "apropiado en tests que contienen ítems multipunto (con varias alternativas de respuesta” (Torninbeni, Pérez y Olaz, 2008:88).

9) La validez de constructo se estimó recurriendo a evidencias provenientes de dos fuentes de información: el contenido del test mediante la validez de contenido (paso 5), y la estructura interna de cada una de las ocho escalas/inteligencias múltiples, 
analizándose su estructura factorial y la proporción de la varianza de las puntuaciones de los sujetos que se puede atribuir a lo que mide cada escala. Se aplicó un análisis factorial exploratorio con la técnica de los componentes principales y rotación varimax, determinándose previamente la idoneidad de la matriz de correlaciones de los reactivos mediante el índice Kayser-Mayer-Olkin (KMO) y el test de esfericidad de Bartlet (Garcia, Gil y Rodriguez, 2000). Asimismo, por razones de la teoría de las inteligencias múltiples se intercorrelacionaron las escalas con el coeficiente $r$ de Pearson para precisar la independencia o no de las mismas. Se asumió un $r>0,60$ como criterio de la existencia de colinealidad.

10) La interpretación psicométrica de las puntuaciones se aseguró elaborando un baremo en puntaje estándar eneatipo (stanine) consistente en un solo dígito sobre una escala de nueve unidades (1 al 9) que tiene una media de 5 y una desviación estándar de 2.

11) Para la contrastación de la hipótesis se correlacionó ( $\mathrm{r}$ de Pearson) las puntuaciones en cada una de las ocho escalas/inteligencias múltiples con las notas obtenidas en escala vigesimal por los integrantes de la segunda muestra en las áreas de matemática; comunicación; inglés; ciencia, tecnología y ambiente; ciencias sociales; persona, familia y relaciones humana; educación física; educación religiosa; arte y educación para el trabajo, componentes del currículo de estudios del Ministerio de Educación. Además, para determinar qué inteligencias múltiples están implicadas en el rendimiento en matemática se empleó la técnica multivariada de regresión múltiple con el procedimiento paso a paso (stepwise).

\section{RESULTADOS}

1) Elaboración del Cuestionario de Inteligencias Múltiples (CUIM).

a) Los resultados del análisis de los ítems concernientes a la capacidad discriminativa de los reactivos de las ocho escalas/inteligencias múltiples del Cuestionario de Inteligencias Múltiples (CUIM), se presentan en la Tabla 1, en la que se anotan las medias aritméticas y desviaciones estándares de cada ítem logradas por la muestra en su conjunto; los tamaños de la prueba T e índices de homogeneidad (IH) de los reactivos y la mediana de estos índices. Es pertinente indicar que por razones de espacio no se presentan las medias y desviaciones típicas alcanzadas en cada ítem por "los grupos extremos" (alto y bajo) según la puntuación total de cada escala/inteligencia múltiple. Como se observa, con la excepción del ítem 10 de la escala/inteligencia múltiple cenestésica "Me han dado un premio o felicitación por una buena actuación en una competencia deportiva” y del ítem 9 de la escala/ inteligencia múltiple naturalista "Participo en actividades de protección del medio ambiente" que tienen valores $\mathrm{T}$ inferiores a 1,96 $(\mathrm{p}>0,05)$, los demás reactivos muestran capacidad discriminativa para diferenciar a los sujetos con puntuaciones altas y bajas en cada una de las escalas/inteligencias múltiples pues sus valores T son mayores a 1,96. Por otro lado, salvo el ítem $8(\mathrm{IH}=0,18)$ de la escala/ inteligencia múltiple intrapersonal "He asistido al psicólogo, orientador o tutor para aprender más sobre mí”, el resto de ítems tienen índices de homogeneidad (IH) superiores a 0,20. De acuerdo al criterio establecido todos los ítems permanecen en sus respectivas escalas. Asimismo, las medianas de los índices de homogeneidad 
(IH) evidencian que la escala/inteligencia múltiple lógico-matemática tiene la mediana más elevada $(0,63)$, y la más baja $(0,38)$ la posee la escala/inteligencia múltiple intrapersonal.

Tabla 1: Medias, desviaciones estándares, valor (T) e índice de homogeneidad (IH) de los ítems de las escalas de Inteligencias Múltiples

\begin{tabular}{|c|c|c|c|c|}
\hline Inteligencia Lingüística & $\bar{X}$ & DE & $\begin{array}{c}\text { Capacidad } \\
\text { discriminativa } \\
T\end{array}$ & $\mathrm{IH}$ \\
\hline $\begin{array}{l}\text { 1. Desde niño(a) he disfrutado mucho el leer } \\
\text { libros, revistas u otros escritos. }\end{array}$ & 4,27 & 1,79 & 20,38 & 0,39 \\
\hline $\begin{array}{l}\text { 2. Aprendo el significado de voces que son } \\
\text { nuevas para mí. }\end{array}$ & 4,90 & 1,63 & 18,82 & 0,38 \\
\hline $\begin{array}{l}\text { 3. Establezco las diferencias que hay entre } \\
\text { palabras con significado parecido. }\end{array}$ & 4.85 & 1,60 & 24,02 & 0,48 \\
\hline $\begin{array}{l}\text { 4. Mis amigos dicen que tengo facilidad para } \\
\text { explicar diversos temas. }\end{array}$ & 4,41 & 1,72 & 22,13 & 0,44 \\
\hline 5. Escribo pequeñas historias, poesías o artículos. & 3,89 & 2,11 & 22,12 & 0,37 \\
\hline $\begin{array}{l}\text { 6. Acostumbro usar una variedad de palabras } \\
\text { cuando hablo o escribo. }\end{array}$ & 4,69 & 1,64 & 24,41 & 0,46 \\
\hline $\begin{array}{l}\text { 7. Prefiero los exámenes en los que pueda } \\
\text { desarrollar por escrito mis respuestas. }\end{array}$ & 4,53 & 2,02 & 17,49 & 0,29 \\
\hline $\begin{array}{l}\text { 8. Soy hábil para recordar largas listas de } \\
\text { palabras. }\end{array}$ & 4,31 & 1,65 & 18,76 & 0,36 \\
\hline $\begin{array}{l}\text { 9. Cuando escribo una composición, escojo las } \\
\text { palabras justas y precisas. }\end{array}$ & 4,70 & 1,70 & 27,18 & 0,53 \\
\hline \multirow[t]{2}{*}{$\begin{array}{l}\text { 10. Al redactar sobre un tema, reflexiono sobre el } \\
\text { orden que deben seguir las palabras. }\end{array}$} & 4,91 & 1,72 & 20,94 & 0,50 \\
\hline & \multicolumn{3}{|c|}{ Mediana } & 0,42 \\
\hline Inteligencia Musical & $\bar{X}$ & DE & $\begin{array}{c}\text { Capacidad } \\
\text { discriminativa } \\
T\end{array}$ & $\mathrm{IH}$ \\
\hline $\begin{array}{l}\text { 1. Desde que era niño(a), la música es lo que más } \\
\text { me ha agradado. }\end{array}$ & 5,61 & 1,75 & 5,20 & 0,42 \\
\hline $\begin{array}{l}\text { 2. Entre las cosas que tengo, lo más importante } \\
\text { son mis discos, casetes CD's o DVD's de } \\
\text { música. }\end{array}$ & 3,97 & 2,06 & 2,88 & 0,37 \\
\hline $\begin{array}{l}\text { 3. Puedo recordar fácilmente las melodías de las } \\
\text { canciones. }\end{array}$ & 5,61 & 1,59 & 7,52 & 0,39 \\
\hline
\end{tabular}


4. Recuerdo cosas, por ejemplo números de teléfonos, cuando sus nombres los repito a un ritmo musical.

5. Cuando escucho música, puedo decir qué instrumentos se están tocando.

$\begin{array}{llll}4,90 & 2,71 \quad 7,87 & 0,28\end{array}$

$\begin{array}{llll}4,67 & 2,68 & 7,63 & 0,34\end{array}$

6. Una de las cosas que hago, es tocar un instrumento musical.

$2,87 \quad 2,14 \quad 5,83 \quad 0,43$

7. Cuando escucho música, puedo decir cuándo una nota no armoniza con las demás.

$\begin{array}{llll}3,41 & 2,07 & 5,68 & 0,51\end{array}$

8. En el lugar que me encuentre, estoy atento a la música que se escuche.

$\begin{array}{llll}5,04 & 2,86 & 5,18 & 0,53\end{array}$

9. La gente dice que tengo "buen oído" para la música o el canto.

$\begin{array}{llll}3,92 & 2,01 & 6,23 & 0,57\end{array}$

10. Creo piezas musicales

$\begin{array}{llll}2,44 & 1,93 & 3,94 & 0,43\end{array}$

Mediana

0,43

\section{Capacidad}

Inteligencia Lógico- Matemática

$\bar{X} \quad \mathrm{DE} \quad \underset{\mathrm{T}}{\operatorname{discriminativa}} \quad \mathrm{H}$

1. Desde niño(a), me han gustado las matemáticas. $\quad 4,22 \quad 2,13$

6,45

0,68

2. Puedo hacer muchos cálculos mentalmente.

$4,20 \quad 1,82$

8,91

0,74

3. Disfruto resolviendo problemas lógicos y enigmas.

$4,15 \quad 2,03$

7,53

0,77

4. Me gusta jugar los juegos que exigen desarrollar el pensamiento lógico.

$4,73 \quad 2,74$

9,42

0,49

5. Con frecuencia me pregunto sobre el porqué de las cosas y busco aclararlas.

5,19

1,70

13,45

0,43

6. Las personas dicen que tengo una "calculadora" en mi cabeza.

$2,94 \quad 1,86$

6,65

0,66

7. Me es fácil resolver problemas matemáticos.

$3,93 \quad 1,89$

5,80

0,73

8. Para mí todo tiene una explicación lógica.

$4,48 \quad 1,88$

10,43

0,55

9. Pienso que las cosas son más claras cuando son medidas o cuantificadas.

$\begin{array}{llll}4,22 & 1,87 & 8,52 & 0,59\end{array}$

10. Descubro fallas lógicas en lo que las personas dicen o escriben.

$\begin{array}{llll}4,30 & 1,87 & 11,11 & 0,56\end{array}$




\begin{tabular}{|c|c|c|c|c|}
\hline Inteligencia Espacial & $\bar{X}$ & DE & $\begin{array}{c}\text { Capacidad } \\
\text { discriminativa } \\
T\end{array}$ & $\mathrm{IH}$ \\
\hline $\begin{array}{l}\text { 1. Desde niño(a), he tenido facilidad para hacer } \\
\text { buenos dibujos. }\end{array}$ & 4,34 & 2,05 & 31,76 & 0,54 \\
\hline $\begin{array}{l}\text { 2. Me agrada diseñar modelos, o hacer maquetas } \\
\text { a escala. }\end{array}$ & 4,08 & 1,99 & 35,71 & 0,62 \\
\hline $\begin{array}{l}\text { 3. Recuerdo mejor la información cuando empleo } \\
\text { gráficos }\end{array}$ & 4,78 & 1,86 & 34,74 & 0,62 \\
\hline $\begin{array}{l}\text { 4. Encuentro fácilmente la ruta apropiada en } \\
\text { zonas que no conozco. }\end{array}$ & 4,99 & 1,73 & 24,98 & 0,51 \\
\hline $\begin{array}{l}\text { 5. Yo puedo imaginar cómo un objeto podría } \\
\text { aparecer en diferentes posiciones. }\end{array}$ & 4,82 & 1,80 & 30,89 & 0,61 \\
\hline 6. Me es fácil leer mapas y trazarlos. & 4,18 & 1,81 & 31,48 & 0,59 \\
\hline $\begin{array}{l}\text { 7. Me gusta resolver los juegos de palabras } \\
\text { cruzadas, laberintos o enigmas visuales. }\end{array}$ & 7,47 & 1,64 & 21,28 & 0,47 \\
\hline $\begin{array}{l}\text { 8. Puedo imaginar con nitidez los lugares que he } \\
\text { visitado. }\end{array}$ & 5,61 & 1,48 & 21,24 & 0,49 \\
\hline $\begin{array}{l}\text { 9. Cuando diseño algo, puedo unir fácilmente sus } \\
\text { partes en mi mente. }\end{array}$ & 4,94 & 1,70 & 33,17 & 0,66 \\
\hline \multirow[t]{2}{*}{$\begin{array}{l}\text { 10. Me gusta desarmar un artefacto y luego } \\
\text { armarlo tal como estaba. }\end{array}$} & 4,81 & 2,16 & 21,86 & 0,39 \\
\hline & \multicolumn{3}{|c|}{ Mediana } & 0,57 \\
\hline Inteligencia Interpersonal & $\bar{X}$ & DE & $\begin{array}{c}\text { Capacidad } \\
\text { discriminativa } \\
T\end{array}$ & $\mathrm{IH}$ \\
\hline $\begin{array}{l}\text { 1. Me considero una persona que puede } \\
\text { solucionar los problemas que pudieran existir } \\
\text { entre mis amigos. }\end{array}$ & 5,24 & 1,58 & 25,06 & 0,52 \\
\hline $\begin{array}{l}\text { 2. Me doy cuenta rápidamente de cómo otras } \\
\text { personas se sienten. }\end{array}$ & 5,78 & 2,21 & 11,18 & 0,35 \\
\hline 3. Las personas me consideran un líder o lideresa. & 4,05 & 1,72 & 21,32 & 0,41 \\
\hline 4. Me resulta fácil hacer amigos/as. & 5,26 & 1,69 & 27,92 & 0,54 \\
\hline $\begin{array}{l}\text { 5. Prefiero los deportes que se juegan en grupo } \\
\text { como el fútbol o el vóleibol. }\end{array}$ & 5,70 & 1,79 & 19,89 & 0,42 \\
\hline
\end{tabular}


6. Trabajo mejor en grupos donde puedo discutir los problemas con otros.

$5,45 \quad 1,63 \quad 25,12 \quad 0,53$

7. Me desagrada trabajar solo.

$4,15 \quad 2,11 \quad 14,95 \quad 0,20$

8. Frecuentemente participo en la organización de actividades sociales, deportivas o culturales.

$\begin{array}{llll}4,40 & 1,97 & 28,36 & 0,49\end{array}$

9. Me desenvuelvo mejor cuando interactúo con otras personas.

$5,18 \quad 1,58 \quad 35,15 \quad 0,63$

10. A menudo comparto mis ideas y sentimientos con otros.

$5,06 \quad 1,78 \quad 25,54 \quad 0,50$

\begin{tabular}{|c|c|c|c|c|}
\hline \multirow[b]{2}{*}{ Inteligencia Intrapersonal } & \multicolumn{3}{|c|}{ Mediana } & 0,50 \\
\hline & $\bar{X}$ & $\mathrm{DE}$ & $\begin{array}{c}\text { Capacidad } \\
\text { discriminativa } \\
T\end{array}$ & $\mathrm{IH}$ \\
\hline $\begin{array}{l}\text { 1. Me doy un tiempo exclusivo para pensar sobre } \\
\text { los grandes asuntos de la vida. }\end{array}$ & 5,43 & 1,58 & 20,29 & 0,40 \\
\hline 2. La gente me ve como una persona solitaria. & 3,27 & 2,01 & 14,04 & 0,21 \\
\hline $\begin{array}{l}\text { 3. He asistido al psicólogo u orientador para } \\
\text { aprender más sobre mí. }\end{array}$ & 2,73 & 2,14 & 12,42 & 0,18 \\
\hline $\begin{array}{l}\text { 4. Tengo una afición o interés especial que guardo } \\
\text { sólo para mí. }\end{array}$ & 4,63 & 2,11 & 22,90 & 0,39 \\
\hline $\begin{array}{l}\text { 5. Normalmente, yo sé cuáles son mis sentimientos } \\
\text { sobre algo. }\end{array}$ & 5,72 & 1,46 & 21,84 & 0,46 \\
\hline $\begin{array}{l}\text { 6. Yo prefiero pasar una tarde libre en casa que } \\
\text { en una fiesta, }\end{array}$ & 4,31 & 2,23 & 22,46 & 0,32 \\
\hline 7. Reconozco con facilidad mis emociones. & 5,50 & 1,48 & 20,81 & 0,43 \\
\hline 8. Me es fácil describir lo que siento. & 5,09 & 1,75 & 20,86 & 0,36 \\
\hline $\begin{array}{l}\text { 9. A menudo, me planteo preguntas acerca de los } \\
\text { valores y creencias de las personas. }\end{array}$ & 4,88 & 1,76 & 25,81 & 0,47 \\
\hline \multirow[t]{2}{*}{ 10. Mi manera de ser afecta el como yo aprendo } & 4,43 & 1,90 & 17,40 & 0,31 \\
\hline & \multicolumn{3}{|c|}{ Mediana } & 0,38 \\
\hline
\end{tabular}

Capacidad

Inteligencia Cenestésica $\quad \bar{X} \quad \mathrm{DE}$ discriminativa $\quad \mathrm{H}$

$\mathrm{T}$

1. Regularmente participo en un deporte o una actividad física.

$\begin{array}{llll}4,86 & 2,05 & 3,59 & 0,59\end{array}$


2. Yo puedo dominar nuevos deportes fácilmente.

$4,72 \quad 1,89$

5,38

0,62

3. Me gusta trabajar haciendo cosas con mis manos.

$\begin{array}{llll}5,33 & 1,72 & 9,06 & 0,31\end{array}$

4. Yo disfruto mucho el baile.

$5,09 \quad 1,98$

2,22

0,29

5. Me agrada estar en buena forma física, por lo cual hago bastante ejercicio.

$\begin{array}{llll}4,72 & 1,78 & 5,03 & 0,57\end{array}$

6 . Desde que estudie la primaria me han gustado las clases de educación física.

$\begin{array}{llll}5,02 & 1,93 & 2,75 & 0,60\end{array}$

7. Frecuentemente hago gestos con las manos u otros movimientos del cuerpo cuando converso con alguien.

$\begin{array}{llll}4,86 & 1,81 & 6,10 & 0,36\end{array}$

8. Tengo tendencia a tocar los objetos para sentir y examinar su textura.

$\begin{array}{llll}4,66 & 1,81 & 9,51 & 0,33\end{array}$

9. Yo tengo una buena coordinación muscular.

10. Me han dado un premio o felicitación por una buena actuación en una competencia deportiva.

$\begin{array}{llll}4,38 & 2,32 & 1,17 & 0,45\end{array}$

\begin{tabular}{|c|c|c|c|c|}
\hline & \multicolumn{3}{|c|}{ Mediana } & 0,47 \\
\hline Inteligencia Naturalista & $\bar{X}$ & DE & $\begin{array}{c}\text { Capacidad } \\
\text { discriminativa } \\
T\end{array}$ & $\mathrm{IH}$ \\
\hline $\begin{array}{l}\text { 1. Me es fácil notar similitudes y diferencias que } \\
\text { hay entre árboles. }\end{array}$ & 4,41 & 1,87 & 11,42 & 0.47 \\
\hline $\begin{array}{l}\text { 2. Puedo reconocer y nombrar diferentes tipos de } \\
\text { pájaros. }\end{array}$ & 3,67 & 1,81 & 7,66 & 0.56 \\
\hline 3. Cuando puedo, prefiero estudiar al aire libre. & 4,63 & 1,98 & 12,31 & 0.52 \\
\hline 4. Distingo y nombro diferentes tipos de plantas. & 3,53 & 1,87 & 9,25 & 0.66 \\
\hline 5. Me gusta sembrar plantas. & 3,62 & 2,11 & 9,85 & 0.62 \\
\hline $\begin{array}{l}\text { 6. Prefiero pasar mi tiempo libre en el campo o } \\
\text { cerca del mar. }\end{array}$ & 5,18 & 1,94 & 10,90 & 0.50 \\
\hline $\begin{array}{l}\text { 7. Desde niño(a) me ha gustado estar en contacto } \\
\text { con la naturaleza. }\end{array}$ & 4,92 & 1,87 & 13,22 & 0.66 \\
\hline
\end{tabular}


8. Aprendería mejor sobre los animales si los observara directamente en el campo.

$\begin{array}{llll}5,32 & 1,81 & 10,22 & 0.56 \\ 2,98 & 1,90 & 0,86 & 0.48 \\ 4,00 & 2,14 & 8,78 & 0.54\end{array}$

9. Participo en actividades de protección del medio ambiente.

10. Disfruto estudiando temas de biología, anatomía, botánica o zoología

Mediana

0,55

b) Consistencia interna. En la Tabla 2 se muestran los coeficientes de consistencia interna de las escalas/inteligencias múltiples.

Tabla 2: Consistencia interna de las escalas del Cuestionario de Inteligencias Múltiples (CUIM).

\begin{tabular}{ccc}
\hline ESCALA & $\mathrm{N}^{0}$ de ítems & alpha \\
\hline Inteligencia Lingüística & 10 & 0,75 \\
Inteligencia Musical & 10 & 0,75 \\
Inteligencia Lógico-Matemática & 10 & 0,88 \\
Inteligencia Espacial & 10 & 0,85 \\
Inteligencia Interpersonal & 10 & 0,78 \\
Inteligencia Intrapersonal & 10 & 0,69 \\
Inteligencia Cenestésica & 10 & 0,79 \\
Inteligencia Naturalista & 10 & 0,85 \\
\hline
\end{tabular}

Respecto de la consistencia interna de las puntuaciones, se observa en la Tabla 2 que los valores de los coeficientes alfa fluctúan de 0,69 (Inteligencia intrapersonal) a 0,88 (Inteligencia lógico-matemática). Si bien está establecido que alfa "puede considerarse como una estimación del límite inferior del coeficiente de fiabilidad de un test" (Muñiz, 1994:50), no hay un acuerdo acerca de su valor mínimo para aceptarlo como adecuado, habiéndose hecho en este sentido varias propuestas; por ejemplo, para Nunally (1987) este valor mínimo sería 0,70. Por su lado, George y Mallery (1995) presentan una gama de intervalos de valores de alfa para evaluar la fiabilidad: por debajo de 0,50, fiabilidad inaceptable; entre 0,50 y 0,60 , fiabilidad pobre; entre 0,60 y 0,70 , fiabilidad de nivel débil; entre 0,70 y 0,80 , fiabilidad aceptable; entre 0,80 y 0,90 fiabilidad de un nivel bueno; un valor superior a 0,90 , fiabilidad excelente. Sin embargo, en torno a este último valor, se señala que un coeficiente alfa más arriba de 0,90 podría indicar mucha redundancia o repetitividad en los ítems (Streiner, 2003, en Morales, 2008).

El cotejo de los valores de los coeficientes alfa con estos intervalos señala que las escalas/inteligencias múltiples lógico-matemática, espacial y naturalista tienen 
coeficientes por encima de 0,80 (fiabilidad buena); en tanto que, las escalas de inteligencia cenestésica, interpersonal, lingüística y musical los tienen por encima de 0,70 (fiabilidad aceptable). Únicamente la escala/inteligencia intrapersonal tiene un coeficiente que es una décima menor que 0,70 , lo que la ubicaría en el límite alto del nivel débil de fiabilidad. Por esta razón, estimamos que en general las cuantías de los coeficientes alfa indican que las escalas/inteligencias múltiples del CUIM tienen consistencias internas adecuadas. Vale decir, que en cada una de ellas, aunque en diferente proporción, un buen porcentaje de la varianza de los sujetos en la puntuación total se debe a lo que los ítems tienen de relacionado, de común, de coherencia en sus respuestas pues los sujetos responden de manera parecida a reactivos diferentes pero que expresan conceptualmente el constructo medido (Morales, 2008), la inteligencia múltiple evaluada. Por ejemplo, el $88 \%$ de las diferencias de las respuestas a los ítems de la escala/inteligencia lógico matemática se debe a que estos covarían, a que tienen bastante de común, a que tienden a medir una misma cosa -conceptualmente la inteligencia lógico matemática-; por otro lado, el $12 \%$ de las referidas diferencias se debe a errores de medición, a lo que los ítems no tienen en común. Sin que necesariamente implique unidimensionalidad de la escala, es atendiendo a lo que los ítems tienen en común que adquiere pleno sentido el sumar las puntuaciones de los ítems para conformar una puntuación total con capacidad diferenciadora para escalar a los sujetos cumpliéndose un principio psicométrico: diferenciar para luego clasificar.

c) Validez. El grado de acuerdo de los 10 jueces que evaluaron la validez de contenido del CUIM especialmente de las escalas/inteligencias múltiples fue medido con el coeficiente V de Aiken (Escurra, 1988). En todos los casos, principalmente en la relevancia (adecuación de los reactivos al constructo medido) y representatividad (distribución proporcional de los reactivos en las escalas), el coeficiente tuvo valores que fluctuaron de 0,85 a 1,00; por lo que asumimos que las escalas/ inteligencias múltiples tienen validez de contenido.

Por otra parte, el análisis factorial tiene sentido cuando las variables están altamente intercorrelacionadas y, a la vez, las variables que tienen correlación muy alta entre sí la tengan con el mismo factor o factores. Si las correlaciones entre las variables son bajas, el análisis factorial sería inaplicable. Los indicadores usuales del grado de asociación entre las variables son el test de esfericidad de Bartlet y el índice de adecuación de muestreo (KMO). El primero tiene por hipótesis nula que la matriz de correlaciones es de identidad, es decir, que las intercorrelaciones valen 0 . El segundo tiene como insumo al coeficiente de correlación parcial que es un indicador de la fuerza de las relaciones entre dos variables eliminando la influencia del resto. En consecuencia, si las variables comparten factores comunes, el coeficiente de correlación parcial entre pares de variables deberá ser bajo, próximos a cero. Por tanto, el índice KMO “compara las magnitudes de los coeficientes de correlación observados con las magnitudes de los coeficientes de correlación parciales" (García, Gil y Rodríguez, 2000:74). Sus valores oscilan entre 0 y 1, aceptándose que si $\mathrm{KMO} \geq 0,75$ la idea de realizar un análisis factorial es buena, si 0,75> 
$\mathrm{KMO} \geq 0,5$ la idea es aceptable y si KMO $<0,5$ es inaceptable (Kayser, 1974, en García, Gil y Rodríguez, 2000).

El test de Bartlet entregó resultados $\chi^{2}$ estadísticamente significativos en todos los niveles de significación $(\mathrm{p}<0,000)$ rechazándose la hipótesis nula de matriz identidad en todas las matrices de intercorrelaciones de los ítems de las escalas/ inteligencias múltiples. Por otra parte, los índices KMO de estas matrices indican que es buena la decisión de aplicar el análisis factorial.

Comprobada la factibilidad de la aplicación del análisis factorial exploratorio, se averiguó la estructura factorial de las escalas/inteligencias múltiples aplicando la técnica de los componentes principales y rotación varimax reteniéndose aquellos factores con eigen value o valor propio superiores a 1. Para asignar los ítems a los factores se estableció que las cargas o saturaciones (loading) de los ítems con el factor tuvieran un valor mínimo de 0,30.

Tabla 3: Estructura factorial de las escalas/inteligencias múltiples del CUIM

ESCALA : INTELIGENCIA LINGÜÍSTICA

Índice Test de

KM O : B art le t: $\quad \mathrm{N}^{\circ}$ de Factores: 2

$0.853 \quad(p<0.000)$

$\%$ de varianza

explicada: 42.09

İ́m $\quad$ Saturación

1. Desde niño(a) he disfrutado mucho el leer libros, revistas u otros escritos.

(F1) 0.477

2. Aprendo el significado de voces que son nuevas para mí.

(F1) 0.585

3. Establezco las diferencias que hay entre palabras con significado parecido.

(F1) 0.635

4. Mis amigos dicen que tengo facilidad para explicar diversos temas.

(F1) 0.581

5. Escribo pequeñas historias, poesías o artículos.

(F1) 0.501

6. Acostumbro usar una variedad de palabras cuando hablo o escribo.

(F1) 0.553

9. Cuando escribo una composición, escojo las palabras justas y precisas.

(F1) 0.670

10. Al redactar sobre un tema, reflexiono sobre el orden que deben seguir las palabras.

(F1) 0.689

7. Prefiero los exámenes en los que pueda desarrollar por escrito mis respuestas.

(F2) 0.856

8. Soy hábil para recordar largas listas de palabras.

(F2) 0.665 
ESCALA : INTELIGENCIA MUSICAL

\begin{tabular}{|c|c|c|c|}
\hline $\begin{array}{l}\text { Índice } \\
\text { K M O : } \\
0.831\end{array}$ & $\begin{array}{l}\text { Test de } \\
\text { B a r t l e t: } \\
(p<0.000)\end{array}$ & $\mathrm{N}^{\circ}$ de Factores: 2 & $\begin{array}{l}\% \text { de varianza } \\
\text { explicada: } 47.74\end{array}$ \\
\hline & & İtem & Saturación \\
\hline
\end{tabular}

5. Cuando escucho música, puedo decir qué instrumentos se están tocando.

(F1) 0.363

6. Una de las cosas que hago, es tocar un instrumento musical.

(F1) 0.764

7. Cuando escucho música, puedo decir cuándo una nota no armoniza con las demás.

(F1) 0.735

9. La gente dice que tengo "buen oído" para la música o el canto.

(F1) 0.614

10. Creo piezas musicales

(F1) 0.794

1. Desde que era niño(a), la música es lo que más me ha agradado.

(F2) 0.738

2. Entre las cosas que tengo, lo más importante son mis discos, casetes o CD de música.

(F2) 0.491

3. Puedo recordar fácilmente las melodías de las canciones.

(F2) 0.781

4. Recuerdo cosas, por ejemplo números de teléfonos, cuando sus nombres los repito a un ritmo musical.

(F2) 0.486

8. En el lugar que me encuentre, estoy atento a la música que se escuche.

(F2) 0.653

ESCALA: INTELIGENCIA LÓGICO MATEMÁTICO

$\begin{array}{llll}\begin{array}{l}\text { Índice } \\ \text { K M O : }\end{array} & \begin{array}{l}\text { Test de } \\ \text { B r l e t: }\end{array} & \mathrm{N}^{\circ} \text { de Factores: } 2 & \begin{array}{l}\text { \% de varianza } \\ \text { explicada: } 61.85\end{array} \\ 0.922 & (\mathrm{p}<0.000) & & \text { Saturación }\end{array}$

1. Desde niño(a), me han gustado las matemáticas.

(F1) 0.839

2. Puedo hacer muchos cálculos mentalmente.

(F1) 0.813

3. Disfruto resolviendo problemas lógicos y enigmas.

(F1) 0.820

4. Me gusta jugar los juegos que exigen desarrollar el pensamiento lógico.

(F1) 0.527

6. Las personas dicen que tengo una "calculadora" en mi cabeza.

(F1) 0.733 
7. Me es fácil resolver problemas matemáticos.

(F1) 0.803

5. Con frecuencia me pregunto sobre el porqué de las cosas y busco aclararlas.

(F2) 0.748

8. Para mí todo tiene una explicación lógica.

(F2) 0.770

9. Pienso que las cosas son más claras cuando son medidas 0 cuantificadas.

(F2) 0.662

10. Descubro fallas lógicas en lo que las personas dicen o escriben.

(F2) 0.662

ESCALA : INTELIGENCIA ESPACIAL

\begin{tabular}{|c|c|}
\hline $\begin{array}{lll}\text { Índice } & \text { Test de } & \\
\text { K M O : } & \text { B a r t l e t: } & N^{\circ} \text { de Factores: } 2 \\
0.89 & (p<0.000)\end{array}$ & $\begin{array}{l}\% \text { de varianza } \\
\text { explicada: } 53.70\end{array}$ \\
\hline Ítem & Saturación \\
\hline 4.Encuentro fácilmente la ruta apropiada en zonas que no conozco. & (F1) 0.634 \\
\hline $\begin{array}{l}\text { 5. Yo puedo imaginar cómo un objeto podría aparecer en diferentes } \\
\text { posiciones. }\end{array}$ & (F1) 0.658 \\
\hline 6. Me es fácil leer mapas y trazarlos. & (F1) 0.568 \\
\hline $\begin{array}{l}\text { 7. Me gusta resolver los juegos de palabras cruzadas, laberintos } 0 \\
\text { enigmas visuales. }\end{array}$ & (F1) 0.688 \\
\hline 8. Puedo imaginar con nitidez los lugares que he visitado. & (F1) 0.720 \\
\hline 9. Cuando diseño algo, puedo unir fácilmente sus partes en mi mente. & (F1) 0.592 \\
\hline 10. Me gusta desarmar un artefacto y luego armarlo tal como estaba. & (F1) 0.472 \\
\hline 1. Desde niño(a), he tenido facilidad para hacer buenos dibujos. & (F2) 0.816 \\
\hline 2. Me agrada diseñar modelos, o hacer maquetas a escala. & (F2) 0.826 \\
\hline 3. Recuerdo mejor la información cuando empleo gráficos & (F2) 0.742 \\
\hline
\end{tabular}

\section{ESCALA: INTELIGENCIA INTERPERSONAL}

\begin{tabular}{|c|c|c|c|}
\hline $\begin{array}{l}\text { Índice } \\
\text { K M O : } \\
0.87\end{array}$ & $\begin{array}{l}\text { Test de } \\
\text { B a r t I e t } \\
(p<0.000)\end{array}$ & $\mathrm{N}^{\circ}$ de Factores: 2 & $\begin{array}{l}\% \text { de varianza } \\
\text { explicada: } 46.35\end{array}$ \\
\hline & & Ítem & Saturación \\
\hline
\end{tabular}


5. Prefiero los deportes que se juegan en grupo como el fútbol o el vóleibol.

(F1) 0.557

6. Trabajo mejor en grupos donde puedo discutir los problemas con otros.

(F1) 0.565

7. Me desagrada trabajar solo.

(F1) 0.578

8. Frecuentemente participo en la organización de actividades sociales, deportivas o culturales.

(F1) 0.682

9. Me desenvuelvo mejor cuando interactúo con otras personas.

(F1) 0.667

10. A menudo comparto mis ideas y sentimientos con otros.

(F1) 0.503

1. Me considero una persona que puede solucionar los problemas que pudieran existir entre mis amigos.

(F2) 0.723

2.Me doy cuenta rápidamente de cómo otras personas se sienten.

(F2) 0.728

3. Las personas me consideran un líder o lideresa.

(F2) 0.555

4. Me resulta fácil hacer amigos/as.

(F2) 0.495

ESCALA : INTELIGENCIA INTRAPERSONAL

$\begin{array}{llll}\text { Índice } & \text { Test de } & & \\ \mathrm{K} \mathrm{M} \mathrm{O}: & \mathrm{B} \text { art le t: } & \mathrm{N}^{\circ} \text { de Factores: } 2 & \begin{array}{l}\text { de varianza } \\ \text { explicada: } 42.37\end{array} \\ 0.77 & (\mathrm{p}<0.000) & & \text { Saturación }\end{array}$

1. Me doy un tiempo exclusivo para pensar sobre los grandes asuntos de la vida.

(F1) 0.632

5. Normalmente, yo sé cuáles son mis sentimientos sobre algo.

(F1) 0.748

7. Reconozco con facilidad mis emociones.

(F1) 0.789

8. Me es fácil describir lo que siento.

(F1) 0.681

9. A menudo, me planteo preguntas acerca de los valores y creencias de las personas.

(F1) 0.543

2. La gente me ve como una persona solitaria.

(F2) 0.661

3. He asistido al psicólogo, orientador o tutor para aprender más sobre mí.

(F2) 0.553

4. Tengo una afición o interés especial que guardo sólo para mí.

(F2) 0.580 
6. Yo prefiero pasar una tarde libre en casa que en una fiesta

(F2) 0.538

10. Mi manera de ser afecta como yo aprendo

(F2) 0.440

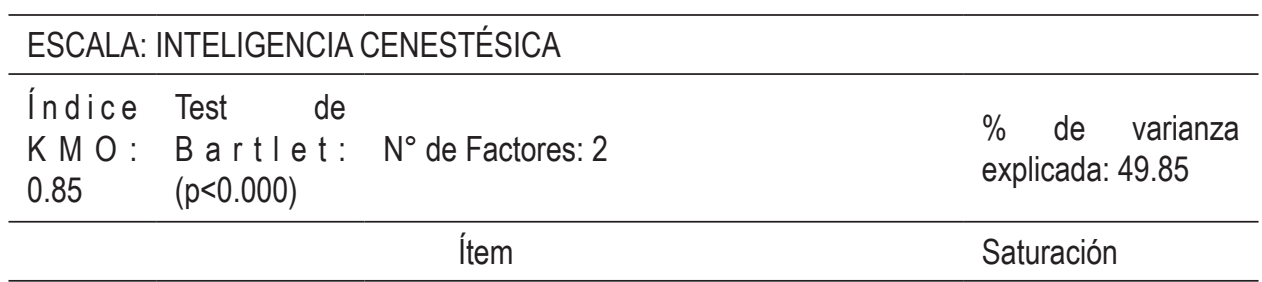

1. Regularmente participo en un deporte o una actividad física.

(F1) 0.813

2. Yo puedo dominar nuevos deportes fácilmente.

(F1) 0.785

9. Yo tengo una buena coordinación muscular.

(F1) 0.469

10. Me han dado un premio o felicitación por una buena actuación en una competencia deportiva.

(F1) 0.708

5. Me agrada estar en buena forma física, por lo cual hago bastante ejercicio.

(F1) 0.661

6. Desde que estudie la primaria me han gustado las clases de educación física.

(F1) 0.733

3. Me gusta trabajar haciendo cosas con mis manos.

(F2) 0.518

4. Yo disfruto mucho el baile.

(F2) 0.466

7. Frecuentemente hago gestos con las manos u otros movimientos del cuerpo cuando converso con alguien.

(F2) 0.743

8. Tengo tendencia a tocar los objetos para sentir y examinar su textura.

(F2) 0.747

ESCALA : INTELIGENCIA NATURALISTA

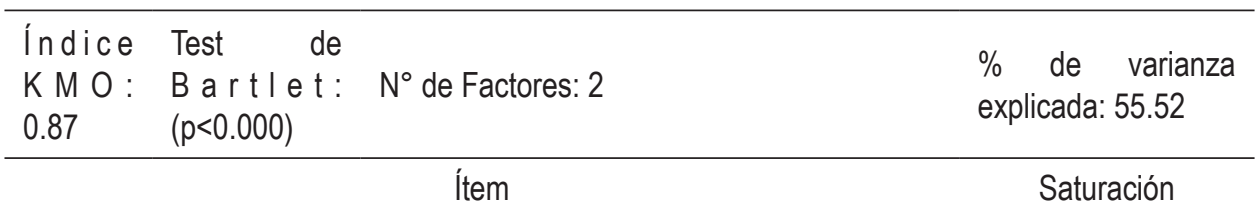

1. Me es fácil notar similitudes y diferencias que hay entre árboles.

(F1) 0.638

2. Puedo reconocer y nombrar diferentes tipos de pájaros.

(F1) 0.832

9. Participo en actividades de protección del medio ambiente.

(F1) 0.552 
10. Disfruto estudiando temas de biología, anatomía, botánica o zoología

(F1) 0.507

4. Distingo y nombro diferentes tipos de plantas.

(F1) 0.804

5. Me gusta sembrar plantas.

(F1) 0.578

3. Cuando puedo, prefiero estudiar al aire libre.

(F2) 0.536

6. Prefiero pasar mi tiempo libre en el campo o cerca del mar.

(F2) 0.834

7. Desde niño(a) me ha gustado estar en contacto con la naturaleza.

(F2) 0.820

8. Aprendería mejor sobre los animales si los observara directamente en el campo.

(F2) 0.713

En la Tabla 3 se observa que a todas las escalas/inteligencias múltiples del CUIM les subyacen dos factores que explicarían las diferencias de las respuestas de los sujetos a los ítems que las conforman. La mediana de los porcentajes explicados de estas diferencias o varianza es $48,79 \%$; por encima de este valor se encuentran los porcentajes explicados por las escalas/inteligencia múltiple lógico-matemática $(61,85 \%)$, naturalista $(55,52 \%)$, espacial $(53,70 \%)$ y cenestésica $(49,85 \%)$; por debajo de este promedio se hallan los porcentajes explicados por las escalas/inteligencia múltiple musical $(47,74 \%)$, interpersonal (46,35\%), intrapersonal $(42,37 \%)$ y lingüística $(42,09 \%)$. Por otra parte, salvo el caso de los ítems "Mi manera de ser afecta como yo aprendo" (inteligencia intrapersonal) y "Yo disfruto mucho el baile" (inteligencia cenestésica) que tuvieron cargas de 0,440 y 0,466, respectivamente, las demás saturaciones de los ítems con sus factores correspondientes fueron en todas las escalas/inteligencia múltiple iguales o superiores a 0,50 lo que propicia una mejor definición de los factores y una mejor interpretación de sus puntuaciones (Comrey, 1985).

Además, de los dos factores que subyacen a todas las escalas/inteligencia múltiple, el primer factor explicó más del $30 \%$ de la varianza y más del doble de la varianza explicada por el segundo factor; también se observó que más del $80 \%$ de los ítems de las escalas ( $100 \%$ en inteligencia espacial y naturalista) saturaron más en el primer factor que en el segundo antes de la rotación (datos no consignados en la tabla 3). Estos datos son importantes pues en interacción con la información de la consistencia interna significan una fuerte evidencia empírica a favor de la unidimensionalidad de las escalas (Morales, 2006), las que medirían un solo constructo.

Por consecuencia de la información analizada en este apartado, puede sostenerse que las escalas/inteligencias múltiples del CUIM tienen validez factorial.

d) Intercorrelación de las escalas. Desde un punto de vista teórico las inteligencias múltiples son independientes entre sí (Gardner, 1987, 2006), aserto que se debería reflejar en las escalas/inteligencias múltiples del CUIM. Empíricamente la 
independencia se puede sopesar intercorrelacionando las referidas escalas usando el coeficiente de correlación de Pearson. Un resultado de 1 entre un par cualesquiera de escalas indicaría colinealidad, que estadísticamente significaría que una variable es una combinación lineal perfecta de la otra, y psicométricamente indicaría una confusión total de lo que supuestamente están midiendo las escala, no podría distinguirse lo que están midiendo una y otra. Como un $\mathrm{r}=1$ es poco probable existen diferentes grados de colinealidad según la fuerza de la relación entre las dos variables. Se han propuesto diversos valores de corte como indicativos de colinealidad problemática, por ejemplo, el de Tacq $(0,60)$ y el de Berry y Feldman $(0,80)$ (Tacq, 1997; Berry y Feldman, 1985, en Cea, 2004). Seleccionamos el valor más conservador 0,60 para señalar colinealidad. En esta circunstancia, los coeficientes resultantes de las intercorrelaciones de las escalas se muestran en la Tabla 4. Se observa que todos los coeficientes alcanzan valores estadísticamente muy significativos $(\mathrm{p}<0.01)$ indicando que las escalas/inteligencia múltiples comparten cierta cantidad de varianza común pero en referencia a su tamaño el más elevado $(r=0,546)$ entre la inteligencia interpersonal y la inteligencia cenestésica es calificado en términos absolutos como "correlación moderada" (Elorza, 1987), y es señal de la no existencia de colinealidad entre las escalas $(\mathrm{r}<0,60)$. Por tanto, empíricamente las escalas/inteligencias múltiples del CUIM miden aspectos bastante independientes entre sí y psicológicamente significativos; lo que a su vez es un respaldo sustantivo a la aseveración de la independencia de las inteligencias múltiples.

En suma, la apreciación de la información concerniente a la validez de contenido, validez factorial e intercorrelación de las escalas así como la generada por el análisis de los ítems y la consistencia interna, hace posible decir que en la población analizada las escalas/inteligencias múltiples del CUIM tienen validez de constructo, vale decir que cada una de ellas mide el constructo objetivo, la inteligencia múltiple correspondiente.

Tabla 4. Coeficientes de correlación de las escalas/inteligencias múltiples del CUIM

\begin{tabular}{|c|c|c|c|c|c|c|c|c|}
\hline & Lin & Mus & LogMat & Esp & Interp & Intrap & Cenes & Natur \\
\hline Lin & -------- & $0.289^{* *}$ & $0.368^{* *}$ & $0.409^{* *}$ & $0.415^{* *}$ & $0.365^{* *}$ & $0.238^{* *}$ & $0.394^{* *}$ \\
\hline Mus & & -------- & $0.123^{\star *}$ & $0.344^{* *}$ & $0.298^{* *}$ & $0.263^{* *}$ & $0.306^{* *}$ & $0.295^{\star *}$ \\
\hline LogMat & & & --------- & $0.391^{* *}$ & $0.209^{* *}$ & $0.232^{* *}$ & $0.203^{* *}$ & $0.238^{* *}$ \\
\hline Esp & & & & --------- & $0.342^{* *}$ & $0.375^{\star *}$ & $0.373^{* *}$ & $0.431^{* *}$ \\
\hline Interp & & & & & -------- & $0.303^{* *}$ & $0.546^{* *}$ & $0.292^{* *}$ \\
\hline Intrap & & & & & & -------- & $0.246^{* *}$ & $0.433^{* *}$ \\
\hline Cenes & & & & & & & ---------- & $0.312^{* *}$ \\
\hline Natur & & & & & & & & -------- \\
\hline $\begin{array}{l}\text { ** }(p<0,01) . \\
\text { Lin = inteligeno } \\
\text { espacial; Interp } \\
\text { inteligencia natt }\end{array}$ & $\begin{array}{l}\text { ngüístic } \\
\text { teligenc } \\
\text { sta. }\end{array}$ & $\begin{array}{l}\text { Aus }= \\
\text { terpers }\end{array}$ & $\begin{array}{l}\text { encia } \\
\text { Intrap }\end{array}$ & $\begin{array}{l}\text { I; Logh } \\
\text { igencia }\end{array}$ & $\begin{array}{l}\text { inteli } \\
\text { eersol }\end{array}$ & lógic & $\begin{array}{l}\text { ática; } \\
\text { cia ce }\end{array}$ & $\begin{array}{l}\text { inteligencia } \\
\text { ica; Natur = }\end{array}$ \\
\hline
\end{tabular}


2) Relación de las inteligencias múltiples con el rendimiento en matemáticas y el rendimiento general.

En términos generales puede decirse que la educación es la ciencia o el arte, mediante el cual cada sociedad inicia a sus nuevos miembros en los valores, conocimientos y técnicas que caracterizan su propia cultura o modo de vida. La educación escolarizada tiene una finalidad intencional y se ejecuta fundamentalmente en el aula (Delgado, 1995), de acuerdo con un plan de acción determinado al servicio de un proyecto educativo que se expresa en el país en el Diseño Curricular Nacional de la Educación Básica Regular (Minedu, 2009) y, en última instancia, en programas curriculares, áreas y materias específicas, por ejemplo la de matemática. La práctica educacional adquiere una dimensión concreta en el proceso de enseñanza-aprendizaje en el que concurren principalmente, pero no únicamente, el alumno, un contenido y el profesor de manera dinámica, intencionada y sistemática que concluye con la ejecución de nuevos comportamientos esperados del alumno, hecho que a su vez se tiene en cuenta para modificar el proceso si es necesario. En la valoración del proceso de aprendizaje del alumno se utiliza distintas formas de evaluación que permiten conocer lo que se denomina rendimiento académico, desempeño académico o rendimiento escolar, términos que en la experiencia docente son utilizados como sinónimos (Edel, 2003), y que están vinculados con una multiplicidad de factores. La estimación del aprendizaje es generalmente cuantitativa mediante las notas o calificaciones escolares, reflejo a su vez -se supone- del resultado de los exámenes o de la evaluación continua, donde el alumno demuestra sus conocimientos sobre las distintas áreas o materias, que el sistema considera necesarias y suficientes para su desarrollo como miembro activo de la sociedad" (Cascón, 2000: 2).

Reconociendo su complejidad adherimos a la siguiente definición de rendimiento académico: "La capacidad respondiente del alumno frente a estímulos educativos, susceptible de ser interpretada según objetivos o propósitos educativos preestablecidos" (Pizarro, 1987, en Andrade, Miranda y Freixas, 2000). A esta capacidad respondiente, valorada por medio de las notas o calificaciones escolares, le subyacería múltiples y diversos factores, entre ellos las inteligencias múltiples, combinados aunque en proporción diferente, algunos más importantes que otros. En este sentido, buscando determinar el rol de las inteligencias múltiples en el rendimiento en matemática y en el rendimiento general de los estudiantes del quinto año de secundaria correlacionamos $(\mathrm{r}$ de Pearson) las puntuaciones del promedio de sus notas escolares en escala vigesimal en las áreas del programa curricular con las puntuaciones que alcanzaron en las escalas/inteligencias múltiples. Tomamos en cuenta los $r>0,20$ pues consideramos que el compartir un $4 \%$ de varianza común es un mínimo aceptable $(0,202=0,04$ $\mathrm{x} 100=4 \%$ ).

Los coeficientes mostrados en la Tabla 5 indican que de 88 correlaciones posibles existen 53 correlaciones estadísticamente significativas, de ellas 41 en el nivel 0,01 y 12 en el nivel 0,05; sin embargo, según el criterio empleado el tamaño absoluto de 51 de las correlaciones es pequeño. Los dos coeficientes que cumplen con el criterio corresponden a la escala/inteligencia múltiple lógico-matemática que correlaciona $0,389 / \mathrm{p}<0,01)$ con el rendimiento en matemática y $0,229(\mathrm{p}<0,01)$ con el rendimiento general. Estos resultados apoyan la hipótesis que la inteligencia lógicomatemática se correlaciona de manera más elevada con el rendimiento en matemática 
que con cualquier otra área y que se correlaciona más con el referido rendimiento que con el rendimiento en general.

Es de notar que esta escala/inteligencia también correlaciona 0,204(p<0,01) con el área ciencia, tecnología y ambiente. Asimismo, que la escala/inteligencia interpersonal no se correlaciona con ninguna de las áreas del programa curricular y que la escala/ inteligencia lingüística correlaciona $0,18(\mathrm{p}<0,01)$. con las áreas de comunicación, educación religiosa, inglés y el promedio general.

Tabla 5: Correlación de las Inteligencias Múltiples con el rendimiento en las áreas del Programa curricular

\begin{tabular}{cccccccccccc}
\hline INTELIGENCIAS & & & & \multicolumn{1}{c}{ AREAS } \\
& Mate & Cta & Comun & Hge & Art & Efis & Erel & Etrab & Pfrh & Ing & Gen \\
\hline Lin & $-0.145^{* *}$ & $0.153^{* *}$ & $0.182^{* *}$ & $0.069^{*}$ & $0.129^{* *}$ & 0.055 & $0.184^{* *}$ & $0.131^{* *}$ & $0.096^{* *}$ & $0.183^{* *}$ & $0.184^{* *}$ \\
Mus & $-0.127^{* *}$ & $-0.134^{* *}$ & $-0.092^{* *}$ & $-0.070^{*}$ & -0.058 & $-0.130^{* *}$ & -0.064 & $-0.118^{* *}$ & -0.047 & -0.061 & $-0.129^{* *}$ \\
LogMat & $0.389^{* *}$ & $0.204^{* *}$ & $0.158^{* *}$ & 0.052 & $0.129^{* *}$ & $0.160^{* *}$ & $0.173^{* *}$ & $0.179^{* *}$ & $0.047^{*}$ & $0.209^{* *}$ & $0.229^{* *}$ \\
Esp & -0.002 & $-0.081^{* *}$ & $-0.146^{* *}$ & $-0.086^{* *}$ & -0.012 & -0.047 & -0.039 & -0.041 & -0.036 & $-0.078^{*}$ & $-0.079^{*}$ \\
Interp & 0.020 & -0.009 & 0.005 & -0.038 & 0.049 & 0.040 & 0.047 & 0.005 & -0.003 & -0.004 & 0.008 \\
Intrap & $-0.069^{*}$ & $-0.079^{*}$ & $-0.093^{* *}$ & $-0.095^{* *}$ & $-0.112^{* *}$ & -0.053 & 0.009 & $-0.099^{* *}$ & -0.050 & $-0.081^{*}$ & $-0.106^{* *}$ \\
Cenes & $-0.077^{* *}$ & $-0.108^{* *}$ & $-0.139^{* *}$ & $-0.114^{* *}$ & -0.048 & 0.047 & $-0.083^{*}$ & $-0.111^{* *}$ & $-0.120^{* *}$ & $-0.126^{* *}$ & $-0.119^{* *}$ \\
Natur & -0.034 & -0.016 & -0.050 & $-0.113^{* *}$ & -0.048 & $-0.080^{*}$ & 0.023 & -0.075 & $-0.082^{*}$ & -0.062 & $-0.081^{*}$ \\
\hline
\end{tabular}

${ }^{* *}(p<0.01) ;{ }^{*}(p<0,05)$

Lin = inteligencia lingüística; Mus = inteligencia musical; LogMat = inteligencia lógico-matemática; Esp = inteligencia espacial; Interp = inteligencia interpersonal; Intrap = inteligencia intrapersonal; Cenes = inteligencia cenestésica; Natur = inteligencia naturalista.

Mate= matemática; $\mathrm{Cta}=$ ciencia, tecnología y ambiente; Comun=comunicación; Ege=historia, geografía y economía, Art=arte, Efis=educación física, Erel=educación religiosa, Etrab=educación para el trabajo, Pfrh= persona, familia y relaciones humanas; Ing=inglés; Gen=promedio general.

Ampliando el análisis del rendimiento en el área de matemáticas decidimos comprobar de manera parsimoniosa qué otras inteligencias múltiples además de la lógico-matemática jugaban un rol importante en su producción. Se efectuó un análisis de regresión múltiple con el método paso a paso (stepwise). Se obtuvieron 6 modelos de regresión, aceptándose el sexto en función del incremento del valor del coeficiente de correlación múltiple $(\mathrm{R})$ y del coeficiente de determinación múltiple ( $\mathrm{R}$ cuadrado corregido), y de hallazgos empíricos sobre las inteligencias múltiples que aparecen en la literatura especializada (Pizarro y Clark, 1995, Pizarro, 2005, Andrade, Miranda y Freixas, 2000, Castro, 2008).

Tabla 6: Rendimiento en matemáticas e Inteligencias Múltiples

\begin{tabular}{cccccc}
\hline Modelo & R & R cuadrado & $\begin{array}{c}\text { R cuadrado } \\
\text { corregido }\end{array}$ & $F$ & Significatividad \\
\hline 6 & 0.492 & 0.242 & 0.236 & 39.6 & $0.000^{*}$ \\
\hline
\end{tabular}

* $(\mathrm{p}<0.000)$. Las inteligencias consideradas en orden de importancia son: inteligencia lógico-matemática, inteligencia cenéstesica, inteligencia musical, inteligencia intrapersonal, inteligencia lingüística e inteligencia espacial. 
En la Tabla 6 se observa que la relación observada en la muestra entre las inteligencias múltiples y el rendimiento en el área de matemática $(R=0,492)$ es cierta, verdadera, que no debe al azar pues el modelo es estadísticamente significativo en todos los niveles de significación según lo comprueba el valor de la prueba $\mathrm{F}$ de Snedecor $(\mathrm{p}<0,000)$. Por su lado, el coeficiente de determinación múltiples ( $R$ cuadrado corregido $=0,236$ ) informa la proporción de la varianza del rendimiento en matemática $(23,6 \%)$ que queda explicada por el conjunto (team) de las inteligencias múltiples del modelo. En otras palabras, este conjunto de inteligencias explica en un 23,6\% las diferencias que en el rendimiento en matemáticas tienen los estudiantes investigados, correspondiendo de este porcentaje el $16,1 \%$ a la inteligencia lógico-matemática. El resultado es importante pues en el rendimiento escolar como se sabe se encuentran implicadas muchas otras variables, por ejemplo las correspondientes al profesor o las condiciones del hogar (Andrade, Miranda, Freixas, 2000), y porque se hace patente la posibilidad de mejorarlo al actuar sobre las inteligencias múltiples implicadas ya que estas pueden ser educables (Gardner, 1987, 2006).

\section{DISCUSIÓN}

En relación al primer objetivo del estudio se desarrolló el Cuestionario de Inteligencias Múltiples (CUIM) (véase el Anexo A) fundamentado teóricamente en la teoría de las inteligencias múltiples de Gardner $(1987,2006)$ y psicométricamente en la teoría clásica de los tests (Spearman, 1954; Muñiz, 1994). La evidencia empírica obtenida de una manera metódica adecuada concerniente a la capacidad discriminativa de los ítems, consistencia interna, validez de contenido, validez factorial, intercorrelación de las escalas/inteligencias múltiples e información derivada de esta evidencia que apunta hacia la unidimensionalidad de cada una de las escalas, hacen del CUIM un instrumento del que puede sostenerse teórica y técnicamente que, en la población de referencia y en otras similares, sus puntuaciones miden con elevado grado de confiabilidad y válidamente las inteligencias múltiples lingüística, musical, lógico-matemática, espacial, interpersonal, intrapersonal, cenestésica y naturalista.

Estimamos que el CUIM es una contribución valiosa en la ruta de sistematización de la medición de las inteligencias múltiples, que por su formato, aplicabilidad y normas (véase el anexo B) será útil para los profesionales de la psicología y la educación dada su potencialidad en el análisis del perfil de las inteligencia múltiples en situaciones educativas, laborales y en las que se considere que su uso sea pertinente. Teniendo presente las limitaciones que en menor o mayor medida tiene todo cuestionario, su buen uso hará posible la elaboración de estos perfiles cómo un sólido apoyo para una mejor apreciación diagnóstica, evaluación y planificación de intervenciones en tales situaciones; tendientes siempre, por ejemplo, a colaborar en el éxito académico del estudiante y también en el éxito del docente.

Con relación al segundo objetivo, la hipótesis de la investigación es apoyada por los resultados empíricos obtenidos. En efecto, la inteligencia lógico-matemática 
se relaciona significativamente más con el rendimiento en matemática que con el rendimiento general del alumno. Sin embargo, siendo en ambos casos las correlaciones estadísticamente significativa $(\mathrm{p}<0,01)$ en tamaño absoluto son modestas lo que era esperable por la naturaleza multifactorial del rendimiento escolar. Análogo resultado encontró Pizarro y Clark (2000) en estudiantes del segundo año de secundaria de Valparaíso; y en referencia solo con el rendimiento en matemática, el resultado es similar al de Pizarro (2005) en alumnos del primer año de secundaria de la misma ciudad, y al de Andrade, Miranda y Freixas (2000) en estudiantes del segundo de secundaria de Santiago de Chile. Es importante añadir que también la inteligencia lógico-matemática se relaciona aunque mucho menos que con la matemática con el rendimiento en el área de ciencia, tecnología y ambiente, relación que igualmente observaban Pizarro y Clark (2000) en la muestra que estudiaron.

Este hallazgo reforzado de los citados investigadores confirma una de las derivaciones de la teoría de las inteligencias múltiples: cada una de ellas debe vincularse más con su área o sector ecológico y cultural, que con otras áreas o sectores, sin que esto naturalmente no implique que en cualquier sector sea necesario el uso de una gama de inteligencias múltiples (Gardner, 2001).

Una explicación más detallada del porqué de la relación del rendimiento en matemática con la inteligencia lógico-matemática (y también de esta con el área de ciencia, tecnología y ambiente) tiene como marco que la teoría de las inteligencias múltiples se concibió como una descripción de los individuos en función de su pasado evolutivo y su supervivencia en nichos ecológicos y culturales (Gardner, 2001), concepción que se refleja en la manera de evaluarlas: la observación por parte de otros de "productos" del sujeto y la autoobservación del sujeto sobre experiencias reales que ha vivido en cada una de las 8 inteligencias múltiples, modalidad esta última que se expresa en el CUIM. En este sentido, la citada relación se explicaría por la vinculación de las características de la matemática escolar con los indicadores de la inteligencia lógico-matemática compendiados en el CUIM. En efecto, según Cokcroft (1985) en el aprendizaje de la matemática juegan roles decisivos el razonar lógica y sistemáticamente, la imaginación, la práctica constante y la disposición afectiva, características que conectan con indicadores que reflejan el gusto y la curiosidad por las matemáticas, la creencia que se tiene en la facilidad para resolver problemas matemáticos y el disfrute de la resolución de problemas que pongan en juego el pensamiento lógico sistematizadamente.

En relación con lo anterior, el análisis del rendimiento en matemática en su covariabilidad con las inteligencias múltiples, encuentra que las diferencias de los estudiantes en este rendimiento se explican en casi una cuarta parte $(23 \%)$ por sus diferencias en la inteligencia lógico-matemática (explica el 16,1\% del $23 \%$ ), inteligencia cenestésica, inteligencia musical, inteligencia intrapersonal, inteligencia lingüística e inteligencia espacial. Este resultado es otra manera de ver la importancia de la inteligencia lógico-matemática en el rendimiento en matemática y la corroboración que en cualquier sector es necesario la puesta en juego de varias inteligencias, pero lo más importante es que este hallazgo servirá 
(así lo esperamos) para una mejor planificación y perfeccionamiento o cambios de las estrategias didácticas para accionar sobre estas inteligencias por la posibilidad teórica de su modificabilidad y así contribuir a la mejora del rendimiento en matemática en el país.

Por otro lado, la relación de la inteligencia lógico-matemática con el rendimiento en general también se hace presente en el estudio de Pizarro y Clark (2000) aunque en estos últimos el rendimiento también se relaciona en segundo lugar con la inteligencia lingüística y en nuestro caso también se produce lo mismo pero la relación siendo estadísticamente significativa es inferior a $0,20(0,18, \mathrm{p}<0,01)$. Asimismo, Solano (2008) en estudiantes secundarios de Buenos Aires encontró que aquellos con buen rendimiento tenían una mayor inteligencia lógico-matemática e intrapersonal. Pareciera entonces que desde el punto de vista de la teoría de las inteligencias múltiples en los sistemas educativos por lo menos de Perú, Chile y Argentina, los estudiantes con mayores habilidades para razonar y disfrutar del pensar sistemático y lógico tendrían elevadas probabilidades de tener éxito, las que se incrementarían si tuvieran habilidades verbales y habilidades para elaborar una percepción precisa de sí mismo, comprendiendo sus sentimientos, intenciones e ideas.

El mayor peso de la inteligencia lógico-matemática y de la inteligencia lingüística en el rendimiento escolar debe ser motivo de una profunda reflexión sobre a qué se debe esta situación; reflexión que ya pedían Pizarro y Clark (2000) para buscar una respuesta a las preguntas “¿mayor tiempo curricular?, ¿importancia real y estimada por los alumnos?, ¿mayor peso factorial o facultades mentales primarias de primera importancia?, ¿mayor dedicación por parte de los alumnos?, ¿se usan más las dos inteligencias en contextos más cercanos y pertinentes?” (p. 8). Pueden añadirse otras cuestiones pero la reflexión es muy necesaria, pues hasta el momento queda al descubierto que contrariamente el espíritu que anima el contenido de los diseños curriculares en el sistema educativo no se aprovecha las otras inteligencias múltiples y con ello no se cumple en la práctica la finalidad de todo sistema educativo: la formación integral del ser humano.

\section{CONCLUSIONES}

1. Se logra la construcción del Cuestionario de Inteligencias Múltiples (CUIM) que tiene puntuaciones confiables, válidas y con normas de interpretación psicométrica que lo hacen un instrumento idóneo para la medición de las inteligencias múltiples de Gardner en la población investigada y en otras de similares características.

2. Los resultados apoyan la hipótesis que la inteligencia lógico-matemática se correlaciona más elevadamente con el rendimiento en matemáticas que con el rendimiento escolar general. Asimismo, se comprueba que esta inteligencia y secundariamente la inteligencia lingüística se relacionan con el rendimiento general; y que en el rendimiento en matemáticas además de la inteligencia lógico-matemática también juegan un rol pero menor las inteligencias cenestésica, musical, intrapersonal, lingüística y espacial. 


\section{REFERENCIAS BIBLIOGRÁFICAS}

Alarcón, R. (2008). Métodos y diseños de investigación del comportamiento. Lima: UPCH.

Ander-Egg, E. (2006). Claves para introducirse en el estudio de las inteligencias múltiples. Santa Fe, Argentina: Homo Sapiens.

Andrade, M., Miranda, C., y Freixas, I. (2000). Rendimiento académico y variables modificables en alumnos de 2do. medio de liceos municipales de la Comuna de Santiago. Consultado el feb 15, 2012 de http://www.propedeutico.cl/data/ upload pub/22958725676689441413. Pdf

Armstrong (2006). Inteligencias múltiples en el aula. Guía práctica para educadores. Barcelona: Paidós Ibérica.

Ary, D.; Jacobs, L.C. y Razavieh, A. (1990). Introduction to research in education (4th. ed.). Chicago, EEUU: Holt, Rinehart and Winston.

Beltrán, J. (1993). Intervención Psicopedagógica. Madrid, España: Pirámide.

Cascón, I. (2000). Análisis de las calificaciones escolares como criterio de rendimiento académico. Consultado el jul 16 de 2010 en http://www.usal.es/ inico/investigacion/ jornadas/jornada2/comun/c17.html

Castro, A. (2008). Las inteligencias múltiples en la escuela, Revista Psicodebate 2: Psicología, Cultura y Sociedad, 2: 23-40. Consultado el Jul 10, 2011 de http://www.palermo.edu/cienciassociales/publicaciones/psicodebate2.html

Cea de Ancona, Ma. (2004). Análisis Multivariable. Teoría y Práctica en la Investigación Social. Madrid: Síntesis.

Clark-Carter, D. (2002). Investigación Cuantitativa. México: Oxford Press.

Cockcroft, W.H. (1985). Las matemáticas si cuentan. Informe Cockcroft. Madrid: Ministerio de Educación y Ciencia.

Comrey, A.L. (1985.) Manual de análisis factorial. Madrid, España: Cátedra.

Chávez, J. (1991). La enseñanza de la matemática en la educación superior. Lima: Universidad de Lima.

Edel, R. (2003). El rendimiento académico: Concepto, investigación y desarrollo: 1-11. REICE - Revista Electrónica Iberoamericana sobre Calidad, Eficacia y Cambio en Educación, Vol. 1, No. 2 Consultado el ene 12, 2011 de http://www.ice.deusto.es/ rinace/reice/vol1n2/Edel.pdf

Elorza, H. (1987). Estadística para ciencias del comportamiento. México, DF, México: Harla.

Evaluación censal $20112^{\circ}$ grado de educación primaria. Consultado el abr 15 de 2012 de http://www2.minedu.gob.pe/umc/ece2011/Informes_ECE_2011/Informes IGDsECE2011/Para_el_Gobierno_Regional_(GR).pdf

Evaluaciones Internacionales PISA - Pisa 2009. Consultado el jun 15, 2011 en http://umc. minedu.gob.pe/?p=235

Delgado, K. (1995). Evaluación y calidad de la educación. Nuevos Aportes. Lima: Logo. 
De Luca, S. (2009). El docente y las inteligencias múltiples. Consultado el jul 262011 en http://www.rieoei.org/deloslectores/616Luca.PDF

Escurra, M. (1988). Cuantificación de la validez de contenido por criterio de jueces. Revista de Psicología, PUCP,6: 103-111.

Flores, J. (1996). Políticas vinculadas al currículo para el desarrollo de la investigación educacional. Informe del I Congreso Nacional sobre diagnóstico y propuestas de investigación educacional en las Universidades del país. Lima: Facultad de Educación de la Universidad Nacional Mayor de San Marcos.

García, E., Gil, J. y Rodríguez, G. (2000). Análisis factorial. Madrid: La MurallaHerpérides.

Gardner H. (2006). Múltiple Intelligences New Horizons. New York : Basic Books.

Gardner, H. (2003). 20 años de las Inteligencias Múltiples: Reflexiones y un plan para el futuro. Consultado el mar 6, $2011 \mathrm{en} \mathrm{http://pzweb.harvard.edu/PIs/HG.htm}$

Gardner, H. (2001). La inteligencia reformulada. Las inteligencias múltiples en el siglo XXI. Barcelona: Paidós.

Gardner H. (1987) Estructuras de la Mente. La teoría de las Inteligencias Múltiples. México: Fondo de Cultura Económica.

Guilford J.P (1986) La naturaleza de la inteligencia humana: Barcelona Paidós Ibérica.

George, D. y Mallery, P. (1995). SPSS/PC+ step by step: A simple guide and reference. Wadsworth Publishing Company. Belmont, CA. Estados Unidos.

Gould, S. (1984). La falsa medida del Hombre. Buenos Aires: Orbis.

Hernández, R.; Fernández, C. y Baptista, P. (2010). Metodología de la Investigación. México: McGraw-Hill.

Martínez, J. (1997). Educación científica y sociedad sustentable. Proyecto Principal de educación en América Latina y el Caribe. Boletín 44, diciembre, 37-43.

Morales, P. (2011). Guía para construir escalas de actitudes. Consultado el feb 18, 2012 de http://www.upcomillas.es/personal/peter/otrosdocumentos/ Guiaparaconstruirescalasdeactitudes.pdf

Morales, P. (2008). Estadística aplicada a las ciencias sociales. Madrid: Universidad de Comillas.

Morales, P. (2006). Medición de Actitudes en Psicología y Educación. Construcción de escalas y problemas metodológicos. Madrid: Universidad Pontificia Comillas.

Neisser, U. (1997). Intelligence: Knows and unknows. Aliaga, J. y Pecho, J. Traductores. Inteligencia. Lo conocido y lo desconocido. Unidad de Postgrado de la Facultad de Psicología de la Universidad Nacional Mayor de San Marcos. Lima, Perú.

Nortes, A. (1993). Un modelo de evaluación diagnóstica en matemáticas. Lérida, España: Universidad de Lérida.

Nunnally, J. (1987). Teoría Psicométrica. México: Trillas. 
Pérez. L. y Jesús. B. (2006) Dos décadas de inteligencia múltiples. Papeles del Psicólogo vol. 27(3),pp.147-164.

Pizarro, R. y Clark, S. (2000). Inteligencia múltiple logico-matemática y aprendizajes escolares científicos. Revista de Psicología, 9(1). Consultado el ene 9, 2012, de http:// www.revistapsicologia.uchile.cl/index.php/RDP/article/viewArticle/18548/19581

Pizarro, R. (2005). Inteligencias Múltiples, Curriculum del Hogar, Intereses, Autoestimas y Logros Académicos Previos y Actuales. Revista de Psicología, 14(2). Consultado el ene 8, 2012, de http://www.revistapsicologia.uchile.cl/index.php/RDP/article/ viewArticle/17430/18188

Riviére, V. (2002). Un informe muy citado. Las Matemáticas sí cuentan. Informe Cockcroft. Consultado el jul 24, 2011 en http://revistasuma.es/IMG/pdf/40/SUMA_40.pdf

Spearman, Ch. (1954). Las habilidades del hombre. Buenos Aires: Paidós.

Shearer, B. (1995). The MIDAS manual. U.S. Departament of Education: Nacional Institutte on Disability and Rehabilitation Research.

Sternberg, R.J. (1985). Implicit theories of intellelligence, creativity and wisdom. Journal of Personality and Social Psychology, 49, 602-627.

Torninbeni, S., Pérez, E., y Olaz, F. (2008). Introducción a la Psicometría. Buenos Aires: Paidós.

Torreblanca, A. (2001). ¿Cuán diferentes son los resultados de las pruebas de matemáticas y de lenguaje en Latinoamérica? Una mirada a través de la Laboratorio Americano de Evaluación de la Calidad Educacional. Crecer. Consultado el mar 6 de 2010 en http://www.minedu.gob.pe/web/el_ministerio/el_ministerio/PlaniEstra/umc/revista/ revcrecer_02.pdf.

Valdés, P.; Valdés, R.; Guisásola, J. y Santos, T. (2002). Implicaciones de las relaciones ciencia-tecnología en la educación científica. Revista Iberoamericana de Educación. $\mathrm{N}^{\circ}$ 28, enero-abril: 101-128. Consultado el mar 8 de 2010 en http// www.campusoei.org/revista/rie28a04. PDFhtm. 


\section{ANEXO 1}

\section{CUESTIONARIO CUIM}

Apellidos y Nombres:

Edad:

Sexo: F-M

Colegio: Distrito:

Grado: Sección: Fecha de Hoy: Día: Mes:

Año:

La asignatura que más me agrado en la secundaria es:

La asignatura que menos me ha agradado en la secundaria es:

\section{INSTRUCCIONES}

A continuación hay una serie de frases. Ud. tiene que decidir si lo dicho en esas frases es o no cierto en su caso. Para responder, use la escala situada abajo. Si piensa que lo dicho en la frase es totalmente cierto en su caso. Marque con una equis (X) el número 7. Si piensa que lo dicho en la frase de ninguna manera es cierto en su caso, marque con una equis $(\mathrm{X})$ el número 1 . Si piensa que lo dicho en la frase es más o menos cierto en su caso, escriba el número entre el 1 y el 7 que mejor lo describa a usted.

$\begin{array}{lllllll}1 & 2 & 3 & 4 & 5 & 6 & 7\end{array}$

De ninguna manera es

cierto en mi caso

Es totalmente cierto en mi caso

Tenga presente que no hay respuesta correctas o erradas, pues cada quien tiene el derecho a poseer su propia opinión. Solamente responda tan precisamente como le sea posible.

\section{FRASES RESPUESTAS}

1. Desde niño(a) he disfrutado mucho el leer libros, revistas u otros escritos.

2. Aprendo el significado de voces que son nuevas para

3. Establezco las diferencias que hay entre palabras con significado parecido.

4. Mis amigos dicen que tengo facilidad para explicar diversos temas.

5. Escribo pequeñas historias, poesías o artículos.

6. Acostumbro usar una variedad de términos palabras cuando hablo o escribo. 
8. Soy hábil para recordar largas listas de palabras.

1234567

9. Cuando escribo una composición, escojo las palabras justas y precisas.

1234567

10. Al redactar sobre un tema, reflexiono sobre el orden que deben seguir las palabras.

1234567

11. Desde que era niño(a), la música es lo que más me ha agradado.

1234567

12. Entre las cosas que tengo, lo más importante son mis discos, casetes o CD's de música.

1234567

13. Puedo recordar fácilmente las melodías de las canciones.

1234567

14. Recuerdo cosas, por ejemplo números de teléfonos, cuando sus nombres los repito a un ritmo musical.

1234567

15.Cuando escucho música, puedo decir qué instrumentos se están tocando.

1234567

16. Una de las cosas que hago es tocar un instrumento musical.

1234567

17. Cuando escucho música, puedo decir cuándo una nota no armoniza con las demás.

1234567

18. En el lugar que me encuentre, estoy atento a la música que se escuche.

1234567

19. La gente dice que tengo "buen oído" para la música o el canto.

1234567

20. Creo piezas musicales

1234567

21. Desde niño(a), me han gustado las matemáticas.

1234567

22. Puedo hacer muchos cálculos mentalmente.

1234567

23. Disfruto resolviendo problemas lógicos y enigmas.

1234567

24. Me gusta jugar los juegos que exigen desarrollar el pensamiento lógico.

1234567

25.Con frecuencia me pregunto sobre el porqué de las cosas y busco aclararlas.

1234567

26. Las personas dicen que tengo una "calculadora" en mi cabeza.

1234567

27. Me es fácil resolver problemas matemáticos.

1234567

28. Para mí todo tiene una explicación lógica.

1234567

29. Pienso que las cosas son más claras cuando son medidas o cuantificadas.

1234567

30. Descubro fallas lógicas en lo que las personas dicen o escriben.

1234567

31. Desde niño(a), he tenido facilidad para hacer buenos dibujos.

1234567

32. Me agrada diseñar modelos, o hacer maquetas a escala.

1234567

33. Recuerdo mejor la información cuando empleo gráficos

1234567

34. Encuentro fácilmente la ruta apropiada en zonas que no conozco.

1234567

35. Yo puedo imaginar cómo un objeto podría aparecer en diferentes posiciones.

1234567

36. Me es fácil leer mapas y trazarlos.

37. Me gusta resolver los juegos de palabras cruzadas, laberintos o enigmas visuales. 
38. Puedo imaginar con nitidez los lugares que he visitado.

39. Cuando diseño algo, puedo unir fácilmente sus partes en mi mente.

40. Me gusta desarmar un artefacto y luego armarlo tal como estaba.

41.Me considero una persona que puede solucionar los problemas que pudieran existir entre mis amigos.

42. Me doy cuenta rápidamente de cómo otras personas se sienten.

43. Las personas me consideran un líder o lideresa.

44. Me resulta fácil hacer amigos/as,

45. Prefiero los deportes que se juegan en grupo como el vóleibol.

46. Trabajo mejor en grupos donde puedo discutir los problemas con otros.

47. Me desagrada trabajar solo.

48. Frecuentemente participo en la organización de actividades sociales, deportivas o culturales.

49. Me desenvuelvo mejor cuando interactúo con otras personas.

50. A menudo comparto mis ideas y sentimientos con otros.

51. Me doy un tiempo exclusivo para pensar sobre los grandes asuntos de la vida.

52. La gente me ve como una persona solitaria.

53. H e asistido al psicólogo u orientador para aprender más sobre mí.

54. Tengo una afición o interés especial que guardo sólo para mí.

55. Normalmente, yo sé cuáles son mis sentimientos sobre algo.

56. Yo prefiero pasar una tarde libre en casa que en una fiesta.

57. Reconozco con facilidad mis emociones.

58. Me es fácil describir lo que siento.

59. A menudo, me planteo preguntas acerca de los valores y creencias de las personas.

60. Mi manera de ser afecta el como yo aprendo.

61. Regularmente participo en un deporte o una actividad física.

62. Yo puedo dominar nuevos deportes fácilmente.

63. Me gusta trabajar haciendo cosas con mis manos.

64. Yo disfruto mucho el baile.

65. Me agrada estar en buena forma física, por lo cual hago bastante ejercicio.

66. Desde que estudie la primaria me han gustado las clases de educación física.

67. Frecuentemente hago gestos con las manos u otros movimientos del cuerpo cuando converso con alguien.

68. Tengo tendencia a tocar los objetos para sentir y examinar su textura. 
69. Yo tengo una buena coordinación manual.

1234567

70. Me han dado un premio o felicitación por buena actuación en una competencia deportiva.

1234567

71. Me es fácil notar similitudes y diferencias que hay entre árboles.

1234567

72. Puedo reconocer y nombrar diferentes tipos de pájaros.

1234567

73. Cuando puedo, prefiero estudiar al aire libre.

1234567

74. Distingo y nombro diferentes tipos de plantas.

1234567

75. Me gusta sembrar plantas.

1234567

76. Prefiero pasar mi tiempo libre en el campo o cerca del mar.

1234567

77. Desde niño(a) me ha gustado estar en contacto con la naturaleza.

1234567

78. Aprendería mejor sobre los animales si los observara directamente en el campo.

1234567

79. Participo en actividades de protección del medio ambiente.

1234567

80. Disfruto estudiando temas de biología, anatomía, botánica o zoología

1234567

\section{POR FAVOR, REVISE SI NO QUEDA POR MARCAR LA RESPUESTA PARA ALGUNA DE LAS FRASES. GRACIAS POR SU PARTICIPACIÓN}

Inteligencia lingüística : 1 - 10; Inteligencia musical: 11-20; Inteligencia lógicomatemática: 21-30; Inteligencia espacial: 31-40; Inteligencia interpersonal: 41-50; Inteligencia intrapersonal: 51-60; Inteligencia cenestésica: 61-70; Inteligencia naturalista: $71-80$ 


\section{ANEXO 2}

\section{BAREMO}

\begin{tabular}{cccccccccc} 
Eneatipo & Lin & Mus & LogMat & Esp & Interp & Intrap & Cenes & Natur & Percentil \\
\hline 9 & $62-70$ & $63-70$ & $65-70$ & $67-70$ & $66-70$ & $63-70$ & $66-70$ & $64-70$ & $96-100$ \\
8 & $57-61$ & $55-62$ & $59-64$ & $62-66$ & $62-65$ & $57-62$ & $61-65$ & $57-63$ & $86-95$ \\
7 & $54-56$ & $52-54$ & $54-58$ & $59-61$ & $59-61$ & $54-56$ & $58-60$ & $53-56$ & $77-85$ \\
6 & $49-53$ & $46-51$ & $47-53$ & $53-58$ & $54-58$ & $49-53$ & $53-57$ & $47-52$ & $60-76$ \\
5 & $44-48$ & $40-45$ & $39-46$ & $46-52$ & $50-53$ & $44-48$ & $47-52$ & $40-46$ & $40-59$ \\
4 & $39-43$ & $34-39$ & $32-38$ & $40-45$ & $43-49$ & $40-43$ & $40-46$ & $33-39$ & $23-39$ \\
3 & $33-38$ & $28-33$ & $25-31$ & $33-39$ & $37-42$ & $35-39$ & $34-39$ & $26-32$ & $11-22$ \\
2 & $28-32$ & $23-27$ & $19-24$ & $26-32$ & $31-36$ & $29-34$ & $26-33$ & $19-25$ & $4-10$ \\
1 & $10-27$ & $10-22$ & $10-18$ & $10-25$ & $10-30$ & $10-28$ & $10-25$ & $10-18$ & $1-3$ \\
Media & 45.53 & 42.35 & 42.31 & 48.02 & 50.23 & 45.98 & 48.39 & 42.23 & Media \\
DE & 9.85 & 11.46 & 13.64 & 11.87 & 10.30 & 9.46 & 11.16 & 12.69 & DE \\
\hline
\end{tabular}

Lin = Inteligencia lingüística; Mus = Inteligencia musical; LogMat = Inteligencia lógico-matemática; $E s p=$ Inteligencia espacial; Interp = Inteligencia interpersonal; Intrap = Inteligencia intrapersonal; Cenes = Inteligencia cenestésica; Natur = Inteligencia naturalista. 